\title{
Cloud radiative forcing of the diurnal cycle climate of the Canadian Prairies
}

\author{
Alan K. Betts, ${ }^{1}$ Raymond Desjardins, ${ }^{2}$ and Devon Worth ${ }^{2}$ \\ Received 30 April 2013; revised 15 June 2013; accepted 20 June 2013; published 29 August 2013.
}

[1] This analysis uses 40 years of hourly observations of temperature (T), relative humidity (RH), and opaque cloud cover from 14 climate stations across the Canadian Prairies to analyze the diurnal cycle climate, represented by the mean $\mathrm{T}$ and $\mathrm{RH}$ and their diurnal ranges. From April to October, when incoming shortwave radiation dominates over longwave cooling, maximum temperature and the diurnal ranges of $\mathrm{T}$ and $\mathrm{RH}$ increase with decreasing opaque cloud cover, while minimum temperature is almost independent of cloud. During the winter period, both maximum and minimum temperatures fall with decreasing cloud, as longwave cooling dominates over the net shortwave flux, which is reduced by the high solar zenith angle and surface reflection by snow. We relate the daily mean opaque cloud cover to the longwave and shortwave cloud forcing and the effective cloud albedo, using multiyear measurements of downward shortwave and longwave fluxes, and longwave fluxes under clear skies from historical weather reanalysis. We provide quadratic fits to compute effective cloud albedo and net longwave fluxes from opaque cloud cover. During the warm season, the daytime rise of temperature is related to the net radiation, and the nighttime fall is related to the net longwave cooling. The diurnal range of $\mathrm{T}, \mathrm{RH}$, and all the net radiative fluxes have a quasi-linear dependence on the effective cloud albedo. This gives a seasonal climate perspective on the coupled land-surface system of T, RH, and cloud cover over the Canadian Prairies, and the winter transitions in snowy climates.

Citation: Betts, A. K., R. Desjardins, and D. Worth (2013), Cloud radiative forcing of the diurnal cycle climate of the Canadian Prairies, J. Geophys. Res. Atmos., 118, 8935-8953, doi:10.1002/jgrd.50593.

\section{Introduction}

[2] A fundamental issue in land-surface climate is how clouds modify the diurnal cycle over the annual cycle. Near the earth's surface, temperature (T) and relative humidity (RH) have a characteristic diurnal cycle, driven by the diurnal cycle of the incoming solar radiation. The atmosphere is relatively transparent to the shortwave radiation from the sun and relatively opaque to the thermal radiation from the earth. The surface is generally warmed by a positive net radiation balance in the daytime and cooled by a negative radiation balance at night. In summer, the daily net radiation balance is positive, but in winter, it is negative. It has been suggested that the climate change signal of rising mean temperatures on multidecadal timescales is dominated by the rise of minimum temperatures, perhaps associated with changes in cloud cover [Karl et al., 1991]. The impact of cloud cover in reducing the diurnal cycle of temperature has been noted by Karl et al. [1987] and Leathers et al. [1998].

\footnotetext{
${ }^{1}$ Atmospheric Research, Pittsford, Vermont, USA.

${ }^{2}$ Agriculture and Agri-Food Canada, Ottawa, Ontario, Canada.

Corresponding author: A. K. Betts, Atmospheric Research, Pittsford, VT 05763, USA. (akbetts@aol.com)

C2013. Her Majesty the Queen in Right of Canada. American Geophysical Union. Reproduced with permission of the Minister of Agriculture and Agri-Food Canada. 2169-897X/13/10.1002/jgrd.50593
}

[3] This surface diurnal cycle over land is such a central feature of the climate system [Betts, 2003] that it is surprising that the dependence on cloud cover over the seasonal cycle is poorly documented, even though we have a good empirical understanding of the impact of clouds on daily timescales. This is because the diurnal cycle climate depends on many coupled processes, and quantitative cloud data are rarely available. The cloud fields have a large impact on both the downward shortwave and longwave radiation at the surface. The boundary layer (BL) clouds are themselves coupled to the diurnal BL evolution, driven by the surface sensible and latent heat fluxes, which in turn depend on the partition of the net radiation that depends in summer on the land-surface vegetation and the availability of water for transpiration. In addition, advection and synoptic variability are large on the daily timescale and may obscure the seasonal diurnal cycle climate.

[4] This paper addresses the cloud radiative forcing of the land-surface diurnal cycle climate over the seasonal cycle using long-term hourly climate records from the Canadian Prairie Provinces. A second paper will address the impact of land use change - changes in agricultural cropping - on the surface energy partition, and how this has changed diurnal and seasonal climate and long-term climate trends in summer.

[5] The Canadian hourly climate data from the early 1950 s to the present are very useful because they contain hourly 
Table 1. Climate Stations: Location and Elevation ${ }^{a}$

\begin{tabular}{|c|c|c|c|c|c|}
\hline Station Name & Station ID & Province & Latitude & Longitude & Elevation $(\mathrm{m})$ \\
\hline Red Deer* & 3025480 & Alberta & 52.18 & -113.62 & 905 \\
\hline Calgary* & 3031093 & Alberta & 51.11 & -114.02 & 1084 \\
\hline Lethbridge $\dagger$ & 3033880 & Alberta & 49.63 & -112.80 & 929 \\
\hline Medicine Hat & 3034480 & Alberta & 50.02 & -110.72 & 717 \\
\hline Grande Prairie* & 3072920 & Alberta & 55.18 & -118.89 & 669 \\
\hline Regina* & 4016560 & Saskatchewan & 50.43 & -104.67 & 578 \\
\hline Moose Jaw & 4015320 & Saskatchewan & 50.33 & -105.55 & 577 \\
\hline Estevan* & 4012400 & Saskatchewan & 49.22 & -102.97 & 581 \\
\hline Swift Current $\dagger$ & 4028040 & Saskatchewan & 50.3 & -107.68 & 817 \\
\hline Prince Albert* & 4056240 & Saskatchewan & 53.22 & -105.67 & 428 \\
\hline Saskatoon* & 4057120 & Saskatchewan & 52.17 & -106.72 & 504 \\
\hline Portage-Southport & 5012320 & Manitoba & 49.9 & -98.27 & 270 \\
\hline Winnipeg*† & 5023222 & Manitoba & 49.82 & -97.23 & 239 \\
\hline The Pas*广 & 5052880 & Manitoba & 53.97 & -101.1 & 270 \\
\hline
\end{tabular}

${ }^{\mathrm{a}}$ Complete data sets are marked with *; stations with $\mathrm{SW}_{\mathrm{dn}}$ are marked with $\dagger$.

observations of opaque cloud cover in tenths. These cloud data enable us to understand land-surface-cloud coupling over both the diurnal and seasonal cycles. In fact, these opaque cloud data are of such good quality that we can calibrate them against multiyear longwave and shortwave radiation data and quantify the coupling of the diurnal cycle of $\mathrm{T}$ and $\mathrm{RH}$ to the longwave and shortwave cloud forcing (LWCF and SWCF). Although these links are all represented by models, the complex feedbacks between model parameterizations and atmospheric dynamics mean that the accuracy of model cloud radiative forcings are hard to assess. Even on the short timescales of forecast models, the development of improved representations of clouds takes long systematic effort [Bechtold et al., 2004, 2008], and their evaluation against observational data is critical [Betts et al., 2006].

[6] In contrast to the model world, this observationally based paper gives reliable insight into the coupling of clouds to the diurnal and seasonal cycle. The land-surface boundarylayer cloud-climate system is fully coupled [Betts, 2009; Wang and Dickinson, 2012], especially in the warm season, when typically a daytime moist convective BL develops, forced by surface heating and evaporation. The analysis framework here is the concept of the land-surface diurnal cycle climate, introduced by Betts and Ball [1995, 1998] for a grassland study, used by Betts et al. [2001] for a boreal forest study and by Betts [2004] to discuss hydrometeorology in global models. For individual days, the diurnal cycle is a combination of local processes and synoptic scale advection. However, if sufficient data are composited, the climate structure more representative of the local energy balance emerges from the synoptic variability. In model data from reanalysis, where all variables are available, it is possible to separate the impact of soil water on evaporative fraction from the impact of clouds on the surface radiation balance [Betts, 2004, 2007; Betts and Viterbo, 2005; Betts et al., 2006, 2007]. In these data sets, we do not have this surface energy partition. We only have the response of the land-surface climate in the coupled system to daily cloud cover, evapotranspiration, and on long timescales changing land use. The Canadian climate data may be unique in having a six-decade record of hourly opaque cloud amount, a measure of reflective cloud, as well as hourly $\mathrm{T}$ and $\mathrm{RH}$, daily precipitation, and snow depth.

[7] Specifically we will answer the question: "How is cloud radiative forcing coupled to the diurnal surface climate; represented by the mean $\mathrm{T}$ and $\mathrm{RH}$, and their diurnal ranges?" This will give a semiquantitative description of the coupled land-surface system of T, RH, cloud cover, and lifting condensation level (LCL) from a seasonal climate perspective. We hope that this analysis will contribute to the improved representation of clouds in many types of coupled models.

[8] Section 2 discusses the processing of the data. In section 3, we use data from Regina to stratify the diurnal cycle by daily mean opaque cloud cover, and then we will generalize our results in section 4 across the Canadian Prairies. Section 5 quantifies the relationships between opaque cloud observations and cloud radiative forcing using measurements of the downward shortwave $\left(\mathrm{SW}_{\mathrm{dn}}\right)$ and longwave $\left(\mathrm{LW}_{\mathrm{dn}}\right)$ fluxes. The synthesis section 6 puts together the different components of our analysis: the reduced diurnal data set for the Prairie climate stations from section 4.1, and the relation between cloud cover and LW and SW radiation fluxes from section 5, and discusses the day and nighttime radiative drivers of the diurnal cycle. We then show that in the warm season, the diurnal range of $\mathrm{T}$, $\mathrm{RH}$, and mean $\mathrm{RH}$, and all the net radiative fluxes driving the diurnal cycle, have a quasi-linear dependence on the effective cloud albedo. Section 7 presents our conclusions.

\section{Data Sets and Processing}

\subsection{Climate Station Data}

[9] We analyzed data from the 14 climate stations listed in Table 1 . These have hourly data, starting in 1953 for all stations except Regina and Moose Jaw which start in 1954. The stations are all at airports. The 11 southern stations from 49 to $52^{\circ} \mathrm{N}$ are in agricultural regions, and the three most northern stations (Prince Albert, The Pas, and Grand Prairie) are either in or close to the boreal forest.

[10] For the first four decades, these hourly data sets are essentially complete, and this will be our primary analysis set to define the diurnal cycle climate. In recent years, cutbacks have introduced gaps in the data at some stations, although nine stations marked with * in Table 1, have maintained continuity. For example, Portage-Southport was the first to stop hourly observations on 1 July 1992 and go to only daytime observations, five days a week. Moose Jaw dropped nighttime observations after July 1998, and Lethbridge and Medicine Hat dropped nighttime 


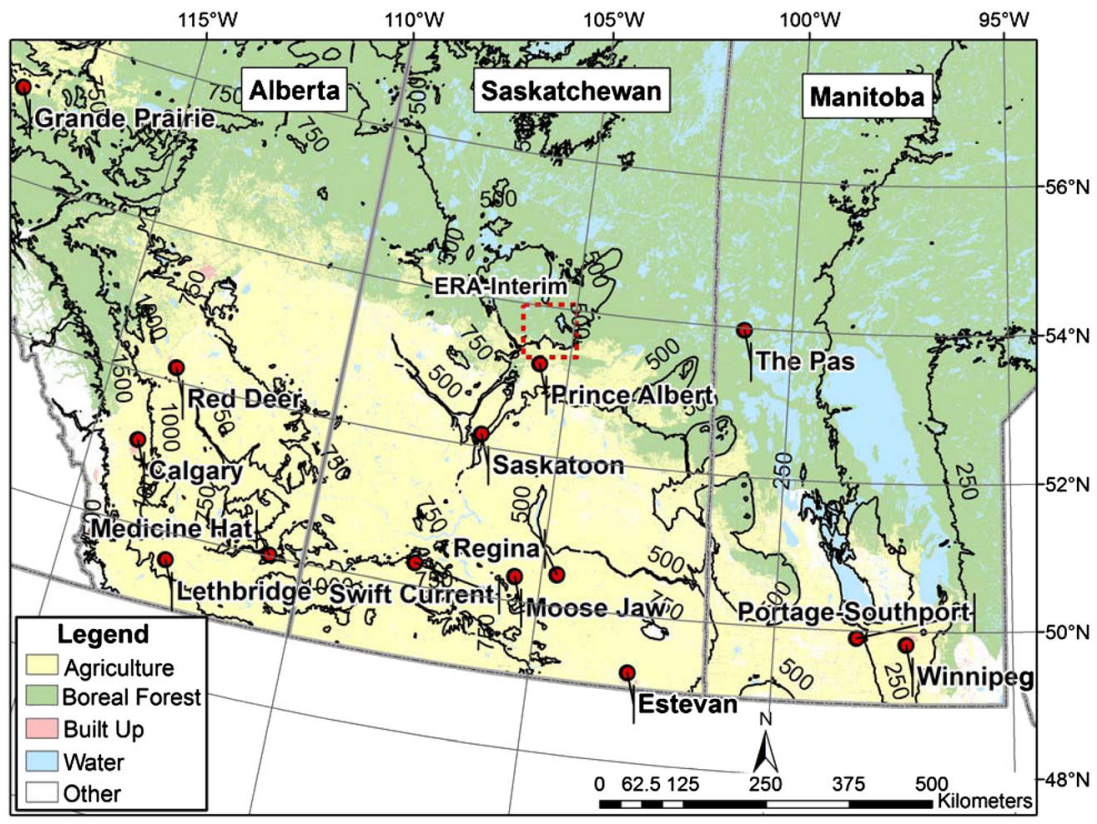

Figure 1. Climate station locations, regional land-cover and $250 \mathrm{~m}$ elevation contours.

observations in April 2006. At the time of processing in 2012, the data sets ran until the summer of 2011. Figure 1 shows the location of the climate stations, regional landcover and the $250 \mathrm{~m}$ elevation contours.

\subsection{Variables and Data Processing}

[11] The hourly climate variables include air pressure (p), dry bulb T, RH, wind speed and direction, total opaque cloud amount, and total cloud amount. Many stations have cloud height data and low cloud amount. Four stations, Lethbridge, Swift Current, The Pas, and Winnipeg) have downward shortwave radiation $\mathrm{SW}_{\mathrm{dn}}$ for some of the period (see 4.1).

[12] We generated a file of daily means of all variables, and extracted and appended to each daily record the corresponding hourly data at the times of maximum and minimum temperature $\left(T_{\max }\right.$ and $\left.T_{\min }\right)$. We merged a file of daily total precipitation and daily snow depth. This we will call the reduced diurnal cycle climate data set. We will use it in sections 3 and 4 to represent the diurnal cycle over the year and across the Prairies. Since occasional hourly data were missing, we kept a count of the number of measurement hours, MeasHr, of valid data in the daily mean. In our results here, we have filtered out all days for which MeasHr $<23$. However, with almost no missing hours of data in the first four decades, there are very few missing analysis days, except for Swift Current, where nighttime data are missing from June 1980 to May 1986.

[13] We define the diurnal temperature range as

$$
\mathrm{DTR}=\mathrm{T}_{\max }-\mathrm{T}_{\min }
$$

[14] We define a diurnal range of $\mathrm{RH}$ from our reduced daily data set as

$$
\Delta \mathrm{RH}=\mathrm{RH}: \mathrm{T}_{\min }-\mathrm{RH}: \mathrm{T}_{\max } \approx \mathrm{RH}_{\max }-\mathrm{RH}_{\min }
$$

[15] This approximation is good for climate means because typically $\mathrm{RH}$ reaches a maximum near sunrise at $\mathrm{T}_{\min }$ and a minimum at the time of $T_{\max }$ (see Figure 3 later). It may be poor at very cold temperatures in midwinter, but then $\Delta \mathrm{RH}$ is very small (see Figure 12 later). We also derived from $\mathrm{p}, \mathrm{T}$, and $\mathrm{RH}$, the $\mathrm{LCL}$, mixing ratio $(\mathrm{Q})$, the pressure height to the $\mathrm{LCL}, \mathrm{P}_{\mathrm{LCL}}$, and the equivalent potential temperature, $\theta_{\mathrm{E}}$.

[16] We used $\mathrm{SW}_{\mathrm{dn}}$ and $\mathrm{LW}_{\mathrm{dn}}$, for the years 1994-1996 from two Boreal Ecosystem-Atmosphere Study (BOREAS) sites at Saskatoon $\left(52.16^{\circ} \mathrm{N}, 106.6^{\circ} \mathrm{W}\right.$, elevation $480 \mathrm{~m}$; $8 \mathrm{~km}$ from the airport climate data) and the Old Aspen site $(\mathrm{OA})$ in the Prince Albert National Park at $53.629^{\circ} \mathrm{N}$, $106.28^{\circ} \mathrm{W}$, elevation $590 \mathrm{~m}(57 \mathrm{~km}$ from the climate station at Prince Albert airport). The OA site was re-instrumented and continued as one of the Boreal Ecosystem Research and Monitoring Sites (BERMS), and we used the data from late 1996 to early 2005, for which we had already computed daily means from the $30 \mathrm{~min}$ data for Betts et al. [2006]. The BOREAS measurements of the radiation fluxes were $15 \mathrm{~min}$ averages, and from these we computed daily means for $\mathrm{SW}_{\mathrm{dn}}$ and $\mathrm{LW}_{\mathrm{dn}}$.

[17] We will use $\mathrm{LW}_{\text {net }}(\mathrm{clear})$ data from the European Center reanalysis known as ERA-Interim [Dee et al., 2011] for a grid point shown in Figure 1, centered at $\left(53.68^{\circ} \mathrm{N}\right.$, $105.56^{\circ} \mathrm{W}$ ), about $43 \mathrm{~km} \mathrm{~N}$ of Prince Albert airport. ERAInterim has a horizontal triangular resolution of $\mathrm{T}_{\mathrm{L}}-255$, which corresponds to a grid cell roughly $80 \mathrm{~km}$ on a side. Appendix B discusses our fits to $\mathrm{SW}_{\mathrm{dn}}$ (clear) and shows a comparison with ERA-Interim and an earlier European Center reanalysis, known as ERA-40 [Uppala et al., 2005].

\subsection{Spatial Representivity of Climate Station Data}

[18] The two stations at Regina and Moose Jaw (see Table 1), which are only $64 \mathrm{~km}$ apart, will be used as an indication of the spatial representivity of the climate data for our analysis. We use the period 1954-1997, when Moose Jaw ceased to make continuous hourly observations. For this period, both stations have nearly complete hourly records, with $99.9 \%$ of days having $\geq 23 \mathrm{~h}$ of data. 

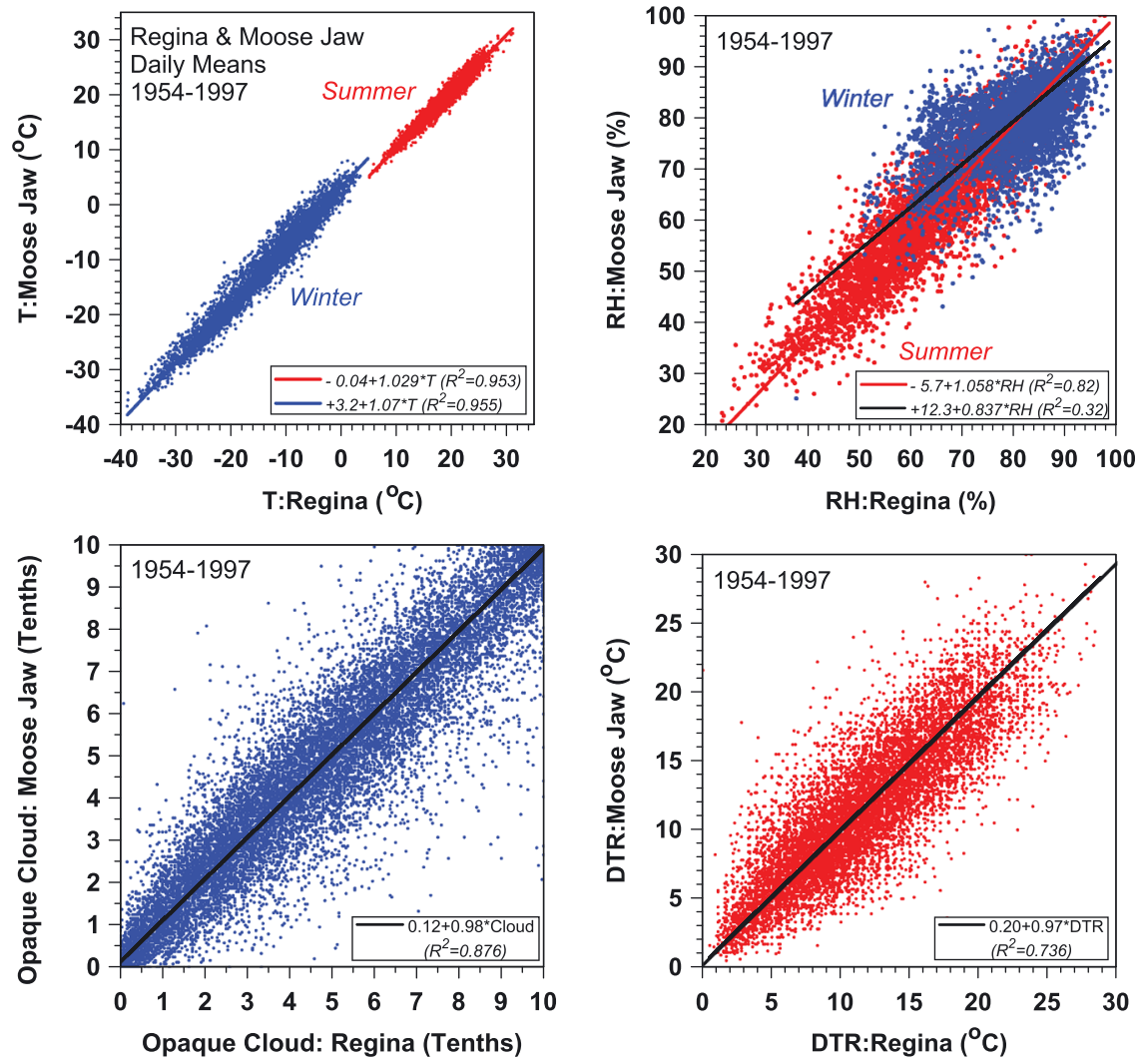

Figure 2. Comparison of daily mean T, RH, opaque cloud, and DTR between Regina and Moose Jaw.

[19] Figure 2 compares daily mean T, RH, opaque cloud cover, and DTR between Regina and Moose Jaw. For T and RH, we show summer (June, July, August) and winter (December, January, February) separately with regression lines for each. The regression lines are the geometric means of the regression of $\mathrm{y}$ on $\mathrm{x}$ and $\mathrm{x}$ on $\mathrm{y}$. Moose Jaw is on average $0.5^{\circ} \mathrm{C}$ warmer in summer and $2.2^{\circ} \mathrm{C}$ warmer in winter than Regina, but the correlation coefficients are similar $\left(\mathrm{R}^{2}=0.95\right)$. Moose Jaw is $2 \%$ drier in summer than Regina, but the two stations are well correlated $\left(\mathrm{R}^{2}=0.82\right)$. In contrast, in winter, both stations have higher humidities, but are poorly correlated $\left(\mathrm{R}^{2}=0.32\right)$. We shall see later large differences in $\mathrm{RH}$ between summer and winter climate regimes.

[20] For DTR and opaque cloud, we show all the data without the summer-winter separation. For DTR, there is no bias between the two stations in either summer or winter. The correlation for all the data shown is $\mathrm{R}^{2}=0.736$. If we separate the seasons, in summer $\mathrm{R}^{2}=0.77$, while in winter $\mathrm{R}^{2}=0.57$.

[21] The mean opaque cloud cover, an atmospheric not a near-surface variable, is estimated hourly by trained observers. For 44 years of independent manual observations, the daily means show remarkably good correlation $\left(\mathrm{R}^{2}=0.876\right)$ and negligible bias between the two stations. This confirms the high quality of these data and also suggests that the daily mean cloud cover in the Canadian Prairies is representative of scales of the order of 50-100 km. It also suggests that the manual observation protocol, described in $M A N O B S$ [2013], has been carefully followed for many decades.

[22] The correlations for $\mathrm{T}$ and $\mathrm{RH}$ are similar (and only slightly poorer) than those shown in Betts et al. [2006] for research quality data in summer from BOREAS for stations separated by up to $81 \mathrm{~km}$. The correlations for opaque cloud are comparable to those for the daily SWCF for these same BOREAS data.

\section{The Diurnal Cycle Climate Over the Year}

[23] We will use Regina to illustrate our diurnal cycle analysis in detail, and then we will generalize our results across the Canadian Prairies in section 4. Some data at Saskatoon are used in section 3.4 to show the coupling between LCL and lowest measured cloud base level.

\subsection{Summer Diurnal Cycle as a Function of Mean Cloud Cover}

[24] Figure 3 shows the June-July-August (JJA) mean diurnal cycle of $\mathrm{T}, \mathrm{RH}, \theta_{\mathrm{E}}$, and $\mathrm{Q}$ for the 40 year period 1954-1993 for Regina, binned by daily mean opaque cloud cover (in tenths). There is an almost monotonic shift of these key thermodynamic variables with cloud cover-with overcast conditions showing some exceptions. This illustrates clearly how long-term composites filter the local dependence of the surface diurnal climate on cloud from the short-time period synoptic variability. In summer, as cloud cover decreases, there is a monotonic increase in $\mathrm{T}_{\max }$, from 14.7 to $27.4^{\circ} \mathrm{C}$, and in the diurnal range. $\mathrm{T}_{\max }$ occurs within an hour of $17 \mathrm{LST}$. In contrast, $\mathrm{T}_{\min }$ decreases only a little with increasing cloud cover and typically occurs at $6 \mathrm{LST}$, close to sunrise. For a fully opaque cloudy sky $(>9 / 10 \mathrm{~s})$, the diurnal cycle is much flatter; the small upward trend of $T_{\min }$ is broken, and $\mathrm{T}_{\min }$ occurs an hour later. It is likely that in fully 

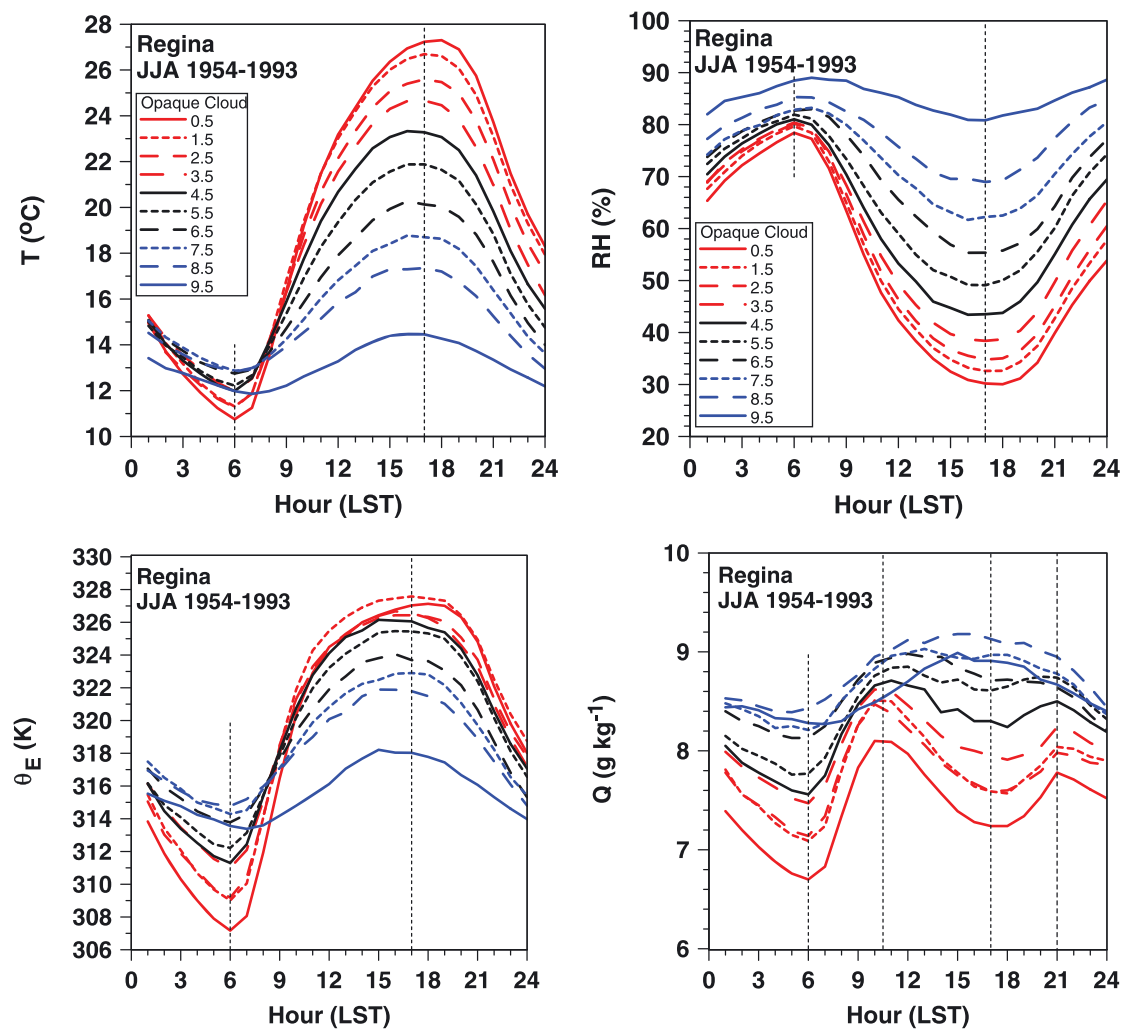

Figure 3. Summer mean diurnal cycle of T, RH, $\theta_{\mathrm{E}}$, and $\mathrm{Q}$, stratified by daily mean opaque cloud cover. Time axis is Local Standard Time (LST).

overcast conditions, advective forcing from changes in weather regimes dominates over local diurnal processes.

[25] As cloud cover decreases, there is a monotonic decrease in RH in summer at all local times (top right). In the mean, the maximum value of $\mathrm{RH}$ occurs at the time of $\mathrm{T}_{\min }$ and falls only $10 \%$ as mean cloud falls. In the mean, the minimum value of $\mathrm{RH}$ occurs at the time of $\mathrm{T}_{\max }$ and falls $50 \%$ as cloud cover decreases. RH is closely coupled to the LCL of near-surface air, which corresponds to the cloud base for BL clouds (see Figure 8 and section 3.4 later).

[26] The bottom left panel shows the diurnal cycle of $\theta_{\mathrm{E}}$. As cloud cover decreases from 8.5 to $0.5 / 10, \theta_{\mathrm{E}}$ increases, but not as much as temperature because $\mathrm{RH}$ is decreasing. The rather flat afternoon $\theta_{\mathrm{E}}$ profile for low cloud cover probably reflects the strong control on $\theta_{\mathrm{E}}$ by the transport of moisture out of the subcloud layer by BL clouds [Betts et al., 2002]. For a fully opaque cloudy sky (>9/10 s), the diurnal cycle patterns for both $\theta_{\mathrm{E}}$ and $\mathrm{Q}$ again do not follow the increasing cloud sequence. We shall see in section 3.3 that daily precipitation increases steeply with increasing cloud cover.

[27] The bottom right panel shows the diurnal range of $Q$ with a minimum at sunrise and the typical morning peak, for cloud cover $<6 / 10 \mathrm{~s}$, about $4.5 \mathrm{~h}$ later at $1030 \mathrm{LST}$. This peak occurs because evapotranspiration is trapped in a shallow layer until the mixed layer breaks through the stable nighttime $\mathrm{BL}$ and mixes down drier air from a residual BL above [Betts et al., 2002]. At 2100 LST, there is a secondary peak of $\mathrm{Q}$, when the surface again uncouples from the mixed layer once the surface temperature falls from the afternoon $\mathrm{T}_{\max }$.
[28] Figure 4 shows the dependence of the diurnal variation of opaque cloud on the daily mean cloud cover. The patterns show a monotonic increase day and night. Opaque cloud cover is always higher in the daytime than at night, which is consistent with increased daytime cloud, forced by surface heating. For broken cloud cover $<6 / 10$, the peak is in late afternoon near the time of $\mathrm{T}_{\max }$. For cloud cover between 6 and $8 / 10 \mathrm{~s}$, the diurnal amplitude is larger and the peak is near local noon. Since these are visual estimates, it is possible that some of the day-night differences could be observational bias.

[29] In summer, days with broken cloud cover predominate, with $66 \%$ of the days having an opaque cloud cover



Figure 4. Diurnal cycle of opaque cloud, stratified by daily mean cloud. 

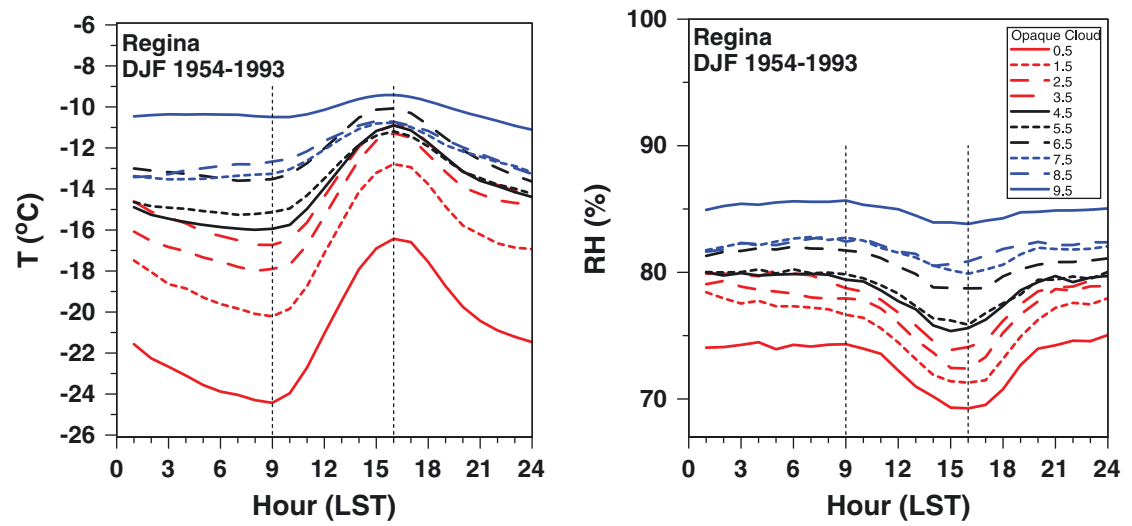

Figure 5. Diurnal cycle of $\mathrm{T}$ and $\mathrm{RH}$ in winter.

$5 / 10$, typical for a shallow cumulus field. The peak in the frequency distribution is $15 \%$ at $2.5 / 10$ opaque cloud (not shown). Only $7.5 \%$ of days are overcast with $>8 / 10$ cloud.

\subsection{Winter Diurnal Cycle of T, RH, and Cloud}

[30] Figure 5 shows the diurnal cycle of T and RH in winter (labeled DJF) for the same 40 year period, stratified by daily mean cloud cover. These are the analogs of the upper panels of Figure 3, but they are quite different. Mean temperatures are of course below freezing, and the diurnal temperature ranges are smaller. However, there is a fundamental difference between the warm season BL, which is deep and well mixed, and the cold season BL which is typically shallow and stratified. Figure 5 shows that as opaque cloud decreases, mean temperatures drop, with $\mathrm{T}_{\min }$ falling faster than $\mathrm{T}_{\max }$, so that the DTR increases with decreasing cloud, as in summer. Remarkably, however, the fall of $\mathrm{T}_{\min }$ of $13.9^{\circ} \mathrm{C}$ in winter with decreasing cloud is larger than the corresponding rise of $\mathrm{T}_{\max }$ of $12.8^{\circ} \mathrm{C}$ in summer. This reflects the dominance of LWCF in winter and SWCF in summer (see section 5). The mean range and diurnal range of $\mathrm{RH}$ are much smaller than in summer. Temperatures are warmest and $\mathrm{RH}$ is highest when cloud cover is $>9 / 10$. The diurnal variation of opaque cloud cover is smaller in winter, when afternoon convective clouds are absent, than in summer (not shown).

\subsection{Reduced Diurnal Cycle Climate Data Set}

[31] This tightly coupled "diurnal climate" structure is the basis for our reduction of the hourly data to a daily data set, summarized in section 2.2. We generated the daily means from the $24 \mathrm{~h}$ data and also extracted $\mathrm{T}_{\max }$ and $\mathrm{T}_{\min }$; and $\mathrm{RH}: \mathrm{T}_{\max }$ and RH: $\mathrm{T}_{\min }$, as well as the cloud cover at the same times. We can see from Figure 3 that in the mean RH: $T_{\max }$ and $\mathrm{RH}: \mathrm{T}_{\min }$ correspond (within a fraction of a percent) to $\mathrm{RH}_{\min }$ and $\mathrm{RH}_{\text {max }}$. On individual days, given synoptic advection, $\mathrm{T}_{\max }, \mathrm{T}_{\min }, \mathrm{RH}_{\max }$, and $\mathrm{RH}_{\min }$ can occur at any time, and their values may depend strongly on advection as well as cloud. However, in long data sets, the smooth dependence of the diurnal cycle climate on cloud emerges. The coupling between clouds and the diurnal cycle shown in Figure 3 can then be simplified to Figure 6.

[32] Figure 6 (left panel, left-hand scale) shows the dependence of $T_{\max }, T_{\text {mean }}$, and $T_{\text {min }}$ on daily mean opaque cloud cover. The standard deviations of the binned daily data are shown for $\mathrm{T}_{\text {mean }}$ : they reflect the variability in the 3680 days of summer data in the composite. The standard deviations are $20 \%$ larger for $T_{\max }$ and $6 \%$ larger for $T_{\min }$, but are omitted for clarity. As daily mean cloud increases, $\mathrm{T}_{\max }$ falls steeply, $\mathrm{T}_{\text {mean }}$ decreases, but $\mathrm{T}_{\text {min }}$ barely changes. Note that $\mathrm{T}_{\text {mean }}$ is close to the average of $\mathrm{T}_{\max }$ and $\mathrm{T}_{\min }$ (see section 4.3 , later).

[33] The opaque cloud cover is a semiquantitative measure of the SWCF, the reduction of the incoming clear-sky


Figure 6. Dependence of $\mathrm{T}_{\max }, \mathrm{T}_{\text {mean }}, \mathrm{T}_{\text {min }}$, and daily precipitation (left) and (right) $\mathrm{DTR}, \mathrm{RH}_{\text {mean }}$, and $\triangle \mathrm{RH}$ on daily mean opaque cloud cover. 


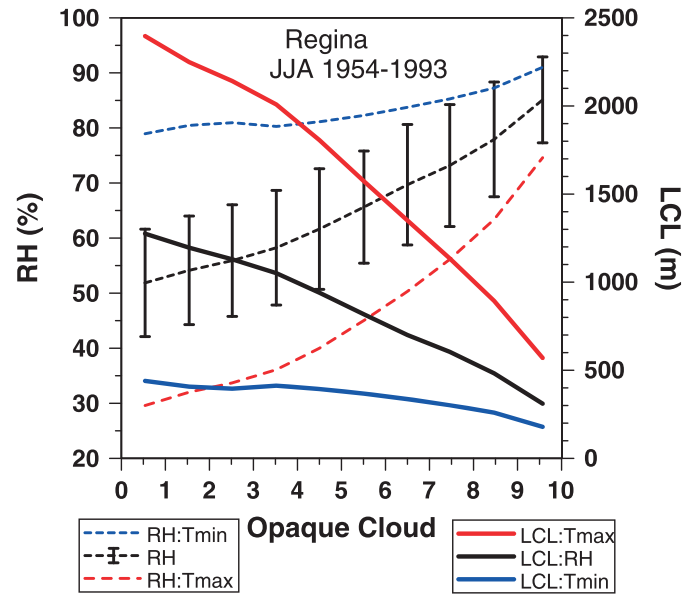

Figure 7. Dependence of RH and computed LCL on opaque cloud cover.

shortwave flux (see section 5.1). So as was clear from Figure 3 , in the summer seasonal climate, $\mathrm{T}_{\max }$ is coupled closely to the SWCF, but $T_{\min }$ is not. We will show in section 4.1 that this is a general result across the Prairies from May to September. The right-hand scale shows the steep rise in mean daily precipitation associated with increasing cloud cover.

[34] Figure 6 (right panel) shows the summer climate coupling between opaque cloud and diurnal temperature range, DTR, on the left-hand scale and $\mathrm{RH}_{\text {mean }}$ and $\Delta \mathrm{RH}$ on the right-hand scale. DTR falls almost linearly with reflective cloud cover, as seen in Amazonian data [Betts and Silva Dias, 2010]. This relationship is tight: the standard deviation of the daily DTR binned by cloud (tenths) is $32 \%$ less than the corresponding standard deviation of $\mathrm{T}_{\max }$ (not shown). Near-surface $\mathrm{RH}_{\text {mean }}$ increases from 50 to $85 \%$, and $\Delta \mathrm{RH}$ falls from 49 to $16 \%$ as cloud cover increases over the full range. The standard deviation of the daily data is about $\pm 11 \%$ for $\mathrm{RH}_{\text {mean }}$ and about $\pm 12 \%$ for $\Delta \mathrm{RH}$ (not shown).

[35] The LCL is tightly linked to RH [Betts, 2009] and falls with increasing RH. The dependence of RH (dotted lines) and LCL (solid lines) on cloud cover for $\mathrm{RH}: \mathrm{T}_{\min }, \mathrm{RH}_{\text {mean }}$, and RH: $\mathrm{T}_{\max }$ is shown in Figure 7. RH: $\mathrm{T}_{\min }$, which is typically $\mathrm{RH}_{\max }$ at sunrise (Figure 3), increases from $79 \%$ to $91 \%$ with increasing cloud cover, and the corresponding LCL falls from $440 \mathrm{~m}$ to $180 \mathrm{~m}$. RH: $\mathrm{T}_{\max }$, which is typically the late afternoon $\mathrm{RH}_{\text {min }}$ (Figure 3), increases from $29 \%$ to $74 \%$ with increasing cloud cover, and the corresponding LCL falls from $2410 \mathrm{~m}$ to $580 \mathrm{~m}$.

[36] So the reduced data show the climatology of the coupling between opaque cloud, RH, and LCL. Not surprisingly, lower cloud cover is associated with lower RH, corresponding to a higher LCL, which in turn usually corresponds to cloud base for BL clouds (see section 3.4). These relations are well known in model data [e.g., Betts and Viterbo, 2005], but we are unaware that there has been much analysis of this fundamental coupling in observational data on climate timescales. T, RH, and cloud cover are all independent measurements, but they are closely linked on the daily timescale through the coupling between land-surface, convective BL, cloud field, and the surface net shortwave and longwave radiation.

\subsection{Relation Between RH ( $\left.T_{\max }\right), \mathrm{LCL}$ and Measured Lowest Cloud Level}

[37] Some of the climate stations (but not Regina) measure the height of the lowest cloud level, so we can confirm the statistical relation to the LCL. Figure 8 plots the measured height of the lowest cloud level $\left(\mathrm{LCB}_{\mathrm{m}}\right)$ against $\mathrm{RH}$ at Saskatoon in summer at the time of $\mathrm{T}_{\max }$. The red line is the calculation of the LCL from the surface RH, found by lifting air dry adiabatically to saturation.

[38] Although there is substantial scatter in these instantaneous $\mathrm{LCB}_{\mathrm{m}}$ measurements, it is clear that the dominant lowest cloud base corresponds closely to the computed LCL, increasing as RH decreases. We conclude that the bases of the opaque clouds will typically correspond to the LCL in summer. This is particularly important to the LWCF since the $\mathrm{LW}_{\mathrm{dn}}$ flux from clouds decreases both as cloud cover decreases, and as LCL increases, because the saturation temperature at cloud base decreases following the dry adiabat from the surface temperature. Across Saskatchewan, "lowest cloud level" opaque cloud corresponds to more than $70 \%$ of the total opaque cloud cover (details not shown).

[39] We have chosen a recent 30 year period because the $\mathrm{LCB}_{\mathrm{m}}$ data have better vertical resolution and less scatter than in the earlier decades. This data set has 2661 days, and the hourly instantaneous data have discrete bins for ( $\mathrm{RH}$, $\left.\mathrm{LCB}_{\mathrm{m}}\right)$ of $(1 \%, 30 \mathrm{~m})$, which gives identical overlap of many points in the band near the red curve. To give a visual appearance that shows the actual data density, the discrete data have been scattered within each bin by adding a random number in the range $( \pm 0-1)$ times half-bin-size of $(0.5 \%, 15 \mathrm{~m})$.

\subsection{Reduced Diurnal Cycle Climate Over the Year}

[40] Figure 9 shows the dependence of $T_{\max }, T_{\min }$, DTR, and precipitation on opaque cloud by month. Although there is a substantial variation in $\mathrm{T}_{\max }$ and $\mathrm{T}_{\min }$, the months from April to October (in red) show a similar coupling to cloud as our summer mean, shown in Figure 6. Specifically, $T_{\max }$ and DTR decrease with increasing opaque cloud cover, but $\mathrm{T}_{\min }$ has little variation. In the transition months of March and November, $T_{\max }$ is flat, while $T_{\min }$ increases with increasing cloud cover. The winter months, December to February (in blue), show that $\mathrm{T}_{\max }$ and $\mathrm{T}_{\min }$ decrease with

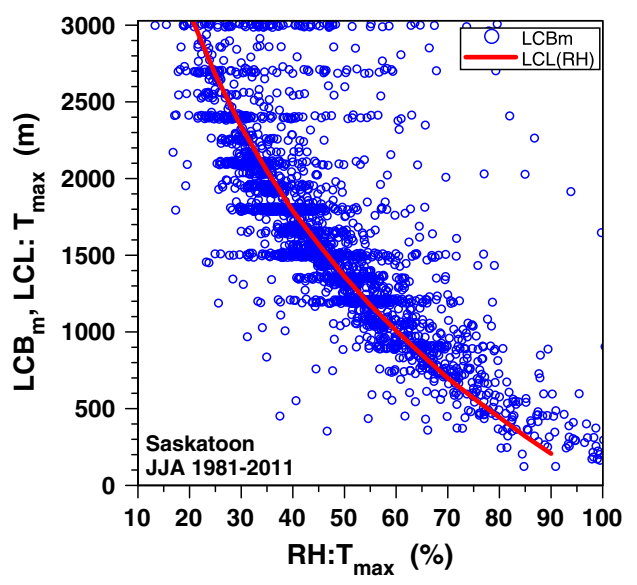

Figure 8. Scatterplot of lowest cloud level $\mathrm{LCL}_{\mathrm{m}}$ and computed LCL (red line) against surface RH at $\mathrm{T}_{\max }$. 
BETTS ET AL.: CLOUD FORCING OF DIURNAL CLIMATE
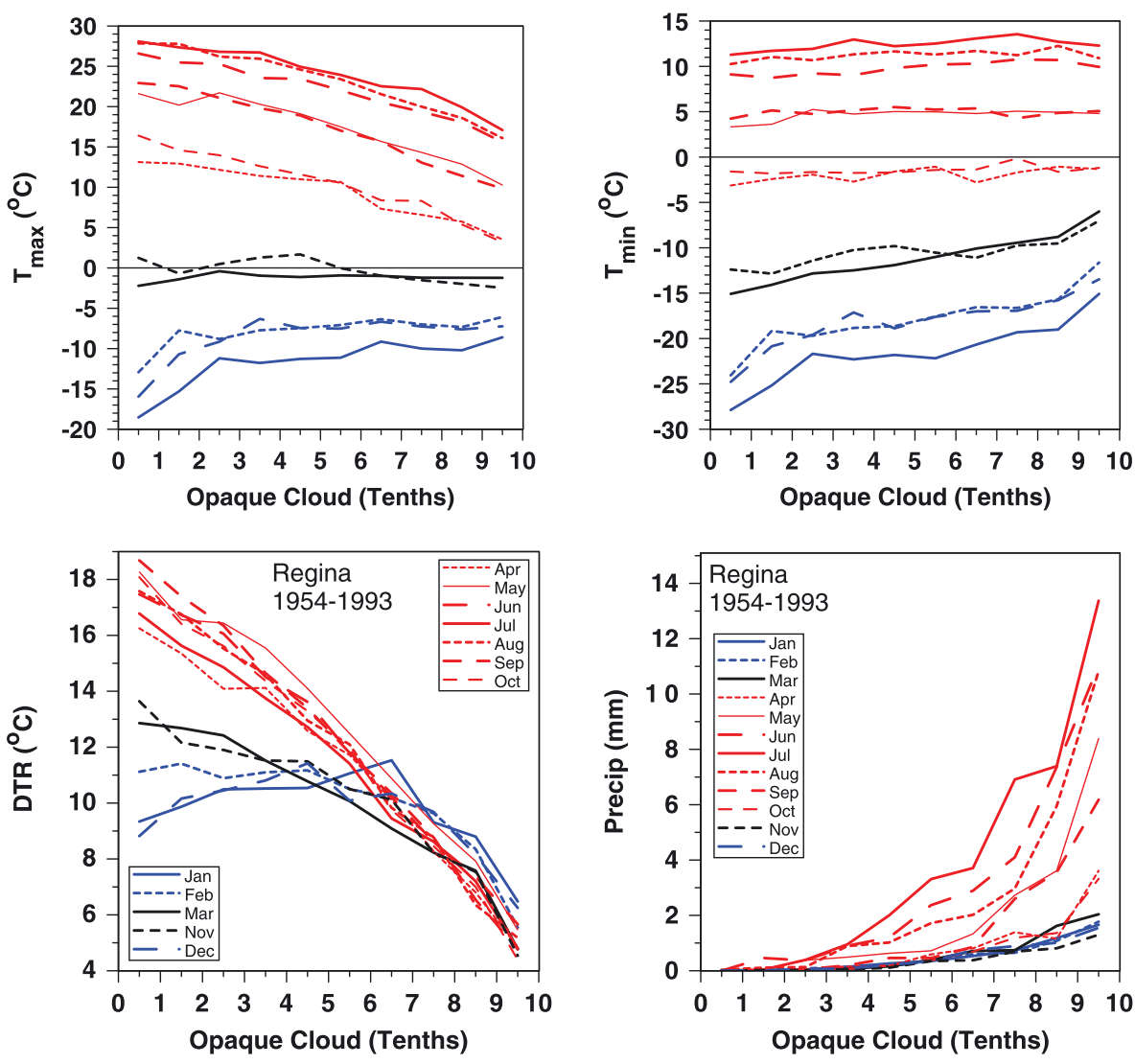

Figure 9. Dependence of $\mathrm{T}_{\max }, \mathrm{T}_{\min }$, DTR, and daily precipitation on opaque cloud by month.

decreasing cloud amount, and DTR does not increase below 6/10 opaque cloud. Precipitation increases with cloud cover in all months with the greatest precipitation in midsummer.

[41] Figure 10 (top panels) shows the dependence of $\mathrm{RH}_{\text {mean }}$ and $\triangle \mathrm{RH}$ by month on opaque cloud. We see a similar grouping of the data by month as in Figure 9. The warmer months, April to October, when the mean temperature is above freezing, cluster together with a large increase of $\mathrm{RH}_{\text {mean }}$ and a fall of $\Delta \mathrm{RH}$ with increasing opaque cloud. From May to September, the spread in the monthly means of the diurnal ranges is extremely small: for DTR about $\pm 1{ }^{\circ} \mathrm{C}$ and for $\Delta \mathrm{RH}$ about $\pm 2 \%$. The diurnal range, $\Delta \mathrm{RH}$, falls sharply through the transition months, March and November, when mean temperatures fall below zero. In the cold winter months, $\triangle \mathrm{RH}$ becomes near zero. $\mathrm{RH}$ is defined here with respect to water saturation; so for reference, we have plotted the ice saturation curve corresponding to winter mean $\mathrm{T}_{\text {min }}$, with its dependence on cloud cover. The diurnally nearly invariant RH curves in winter are approaching this ice-saturation curve.

[42] Figure 10 (lower panels) shows monthly snow depth and percent of days with snow cover, and the mean change in $\mathrm{T}_{\max }, \mathrm{T}_{\min }$, and $\Delta \mathrm{RH}$ with the first lasting snow events, typically in November.

[43] The lower left panel shows that the months May to September are snow free, and in April and October, fewer than $20 \%$ of the days have any snow cover. The rapid transition in March and November occurs when $\mathrm{T}_{\text {mean }}$ is below freezing and the ground is mostly snow covered. This suggests that the diurnal cycle is coupled to the winter climate transition [Betts, 2011], when the first lasting snow cover has a large local climate impact. These are illustrated in the lower right panel, which is a 39 year composite of the week before and after the first lasting snowfall, which on average occurs in mid-November. Over three days including the snow event, $\mathrm{T}_{\max }$ falls about $8^{\circ} \mathrm{C}$ and $\mathrm{T}_{\min }$ about $5^{\circ} \mathrm{C} . \Delta \mathrm{RH}$ falls from about $20 \%$ to its typical winter value below $5 \%$.

[44] The much higher albedo of the snow greatly reduces the surface $\mathrm{SW}_{\text {net }}$ and the SWCF (section 5), and the sublimation from the frozen surface is much less than the evaporation in the previous warmer month, so $\Delta \mathrm{RH}$ becomes small. On regional scales, tropospheric water vapor falls, and this increases the outgoing net longwave. Essentially, the water vapor greenhouse effect is reduced. The snow cover also partially insulates and uncouples the ground from the atmosphere. All three processes cause the surface air temperature to fall with snow cover. The rapid transition in March is the reverse, as the surface and atmosphere warm in response to the decreasing solar zenith angle. As $\mathrm{T}_{\max }$ rises above zero, the reflective snow melts, and surface evaporation from the wet ground increases steeply.

\section{Generalization to the Canadian Prairie Climate}

[45] The relationships seen for Regina are broadly representative of the Canadian Prairies. For each of the 14 climate stations in Table 1, we derived a snow-free warm season average for the months May to September and a cold season average of the months November to March for the 41/40 year period from 1953/1954 to 1993, omitting the months of April and October. Then we combined groups of these stations to show a mean and standard deviation of the group. 

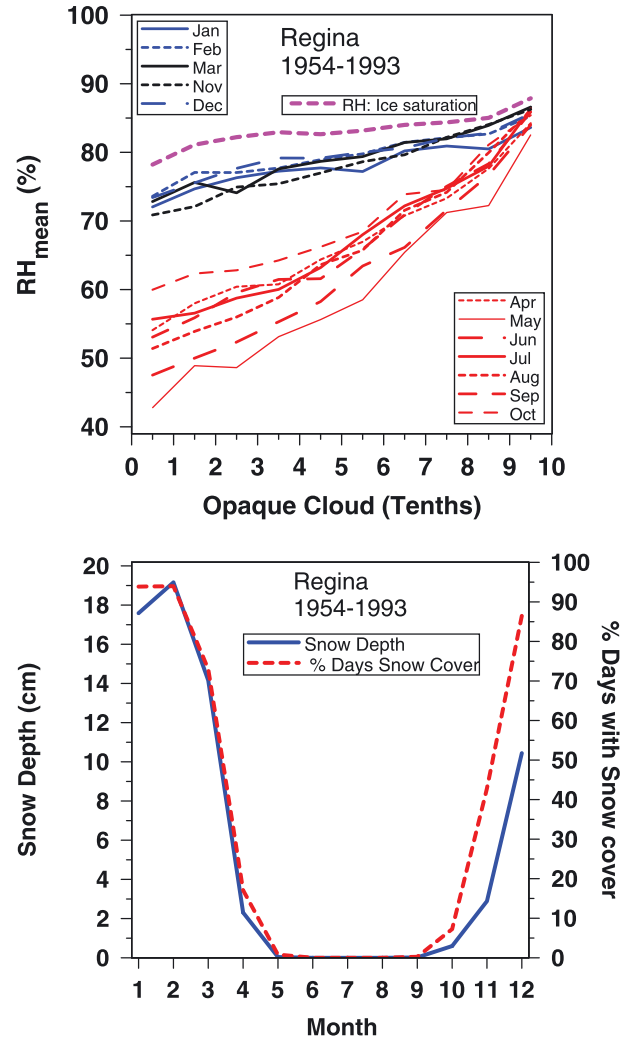
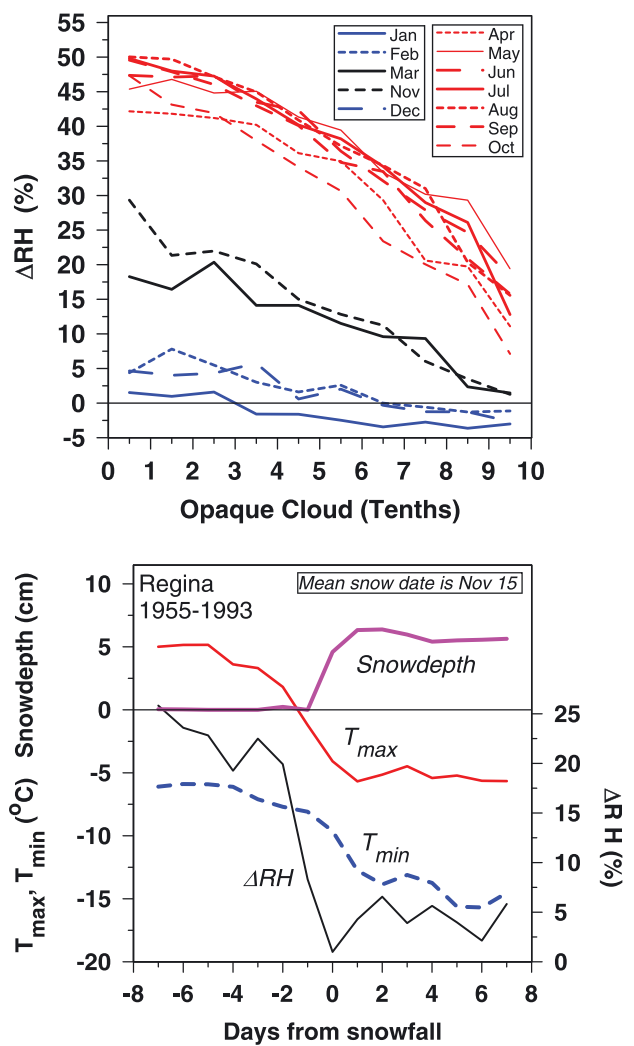

Figure 10. Dependence of RH and $\Delta \mathrm{RH}$ by month on opaque cloud (top) and (bottom) monthly snow cover and mean transition through the first lasting snowfall.

\subsection{Warm Season: May to September}

[46] Figure 11 shows the coupling for the snow-free warm season, May to September, between opaque cloud cover, DTR and daily precipitation (left panel) and (right panel) the diurnal humidity range and the LCL corresponding to the afternoon $\mathrm{RH}: \mathrm{T}_{\max }$. The group of 12 Prairie climate stations is Calgary, Grand Prairie, Lethbridge, Medicine Hat, and Red Deer in Alberta; Estevan, Moose Jaw, Prince Albert, Regina, Saskatoon and Swift Current in Saskachewan, and Winnipeg in Manitoba. We omitted Portage, which has no precipitation data, and The Pas, which is near the southern edge of the boreal forest.

[47] Our reduced diurnal cycle data set clearly defines the characteristic features of the diurnal cycle. The standard deviations across the 12 climate stations in these warm season means across the Prairies are remarkably small. For $\mathrm{T}_{\max }$ and $\mathrm{T}_{\min }$, the standard deviations are $\approx 1{ }^{\circ} \mathrm{C}$, and for $\mathrm{RH} \approx 3-4 \%$. For the difference variables, they are even smaller: for DTR $\approx 0.5^{\circ} \mathrm{C}$ and for $\Delta \mathrm{RH} \approx 1.5 \%$.

[48] Figure 11 shows that the opaque cloud dependence of the diurnal cycle climate for Regina is representative of the Prairies in the warm snow-free season. We can draw three important conclusions. Warm season $T_{\max }$ and $T_{\text {mean }}$ decrease with increasing opaque cloud cover, but $\mathrm{T}_{\min }$ does not. The diurnal ranges, DTR and $\Delta \mathrm{RH}$, are tightly coupled to cloud cover, and both decrease monotonically with increasing cloud. Increasing cloud cover is tightly coupled to increasing RH and decreasing afternoon LCL, as well as increasing daily precipitation.

\subsection{Cold Season: November to March}

[49] Unlike summer, there is substantial variation in winter in temperatures across the Prairies, so we will show two groups of stations. The three stations Calgary, Lethbridge, and Medicine Hat in Alberta form one group that is substantially warmer in winter. We will contrast them with a second group of nine stations (Estevan, Grand Prairie, Moose Jaw, Prince Albert, Portage, Regina, Saskatoon, The Pas, and Winnipeg) with colder winter temperatures. Two stations, Red Deer, and Swift Current, which fall between the two groups in winter temperatures, are omitted.

[50] Figure 12 (left panel) shows that the difference between the two groups in $\mathrm{T}_{\max }$ (red curves) and $\mathrm{T}_{\min }$ (blue curves) increases from near zero for overcast skies to more than $-10^{\circ} \mathrm{C}$ as cloud cover falls. At the same time, the "warm" Alberta group has a greater diurnal temperature range at low cloud cover. The right panel shows that $\Delta \mathrm{RH}$ is very small for the cold group, but much larger for the warm group, where $T_{\max }$ is only just below zero. These changes in pattern with cloud cover, seen here between cold and warm groups resemble the differences seen in Figures 9 and 10 at Regina between the coldest winter months and the transition months, November and March, when $\mathrm{T}_{\max } \approx 0^{\circ} \mathrm{C}$. In fact the "warm" Alberta group has snow cover only $51 \%$ of the days from November to March, and a mean snow depth of only $4.5 \mathrm{~cm}$, whereas the colder group of stations has snow cover for $79 \%$ of the days and a mean snow depth of $16 \mathrm{~cm}$. We conclude that temperature with respect to freezing and snow cover critically affect the diurnal cycle in winter. 



Figure 11. Warm season coupling between opaque cloud and $T_{\max }, \mathrm{T}_{\text {mean }}$, and $\mathrm{T}_{\min }$. DTR and precipitation (left) and (right) $\mathrm{RH}: \mathrm{T}_{\min }, \mathrm{RH}: \mathrm{T}_{\max }, \mathrm{RH}_{\text {mean }}, \triangle \mathrm{RH}$, and LCL: $\mathrm{T}_{\max }$. Standard deviations are between the 12 stations.

4.3. Relation Between $\mathrm{T}_{\text {mean }}$ and $\mathbf{R} \mathrm{H}_{\text {mean }}$ and Maximum and Minimum Values

[51] Wang and Zeng [2013] have noted that for many sites

$$
\operatorname{AvT}=\left(\mathrm{T}_{\text {max }}+\mathrm{T}_{\text {min }}\right) / 2 \neq \mathrm{T}_{\text {mean }}
$$

[52] This is an important issue because, where hourly data are unavailable, some climate data records make the approximation $A v T \approx T_{\text {mean }}$. Since we have computed the true daily $\mathrm{T}_{\text {mean }}$ from the hourly data, we can explore as a function of opaque cloud and season the bias of AvT, defined as

$$
\mathrm{T}_{\text {bias }}=\mathrm{AvT}-\mathrm{T}_{\text {mean }}
$$

[53] Similarly, for RH, we may define the bias

$$
\mathrm{RH}_{\text {bias }}=\mathrm{AvRH}-\mathrm{RH}_{\text {mean }} \text {. }
$$

where $A v R H=\left(R H: T_{\max }+R H: T_{\min }\right) / 2$ which is our reduced data set approximation to $\left(\mathrm{RH}_{\min }+\mathrm{RH}_{\max }\right) / 2$.

[54] Figure 13 (left panel) shows the distribution of the mean $\mathrm{T}_{\text {bias }}$ with opaque cloud cover for the warm season,
May to September (MJJAS), and the cold season November to March (NDJFM), together with the bias of all the data. First, we created these mean biases for each of the climate stations and then found the mean and standard deviation across the set of 14 stations. Remarkably, warm and cold seasons have the reverse patterns with increasing cloud. This may be due to the decrease in day length from summer to winter, or because the cloud radiative forcing reverses sign between warm and cold seasons (see section 5). At low cloud cover in summer, AvT is an underestimate of $\mathrm{T}_{\text {mean }}$, but in winter, it is an overestimate, whereas at high cloud cover, AvT is biased high in summer and low in winter. The mean biases are shown in the legend. The mean bias of AvT over all stations is $-0.10 \pm 0.11^{\circ} \mathrm{C}$.

[55] Figure 13 (right panel) shows the corresponding distributions for the $\mathrm{RH}_{\text {bias }}$. We again see a reverse bias at low cloud cover in the warm and cold seasons, and a pattern reversal at high cloud cover. The mean bias of AvRH over all days is only $-1.0 \pm 0.8 \%$. Figure 13 shows that using AvT or AvRH as an estimate of the mean introduces small biases that depend on cloud cover and on season, but are similar in structure across the Canadian prairies. Nonetheless, the mean annual biases of about $0.1^{\circ} \mathrm{C}$ and $1 \%$ are rather small in this multidecadal data set.
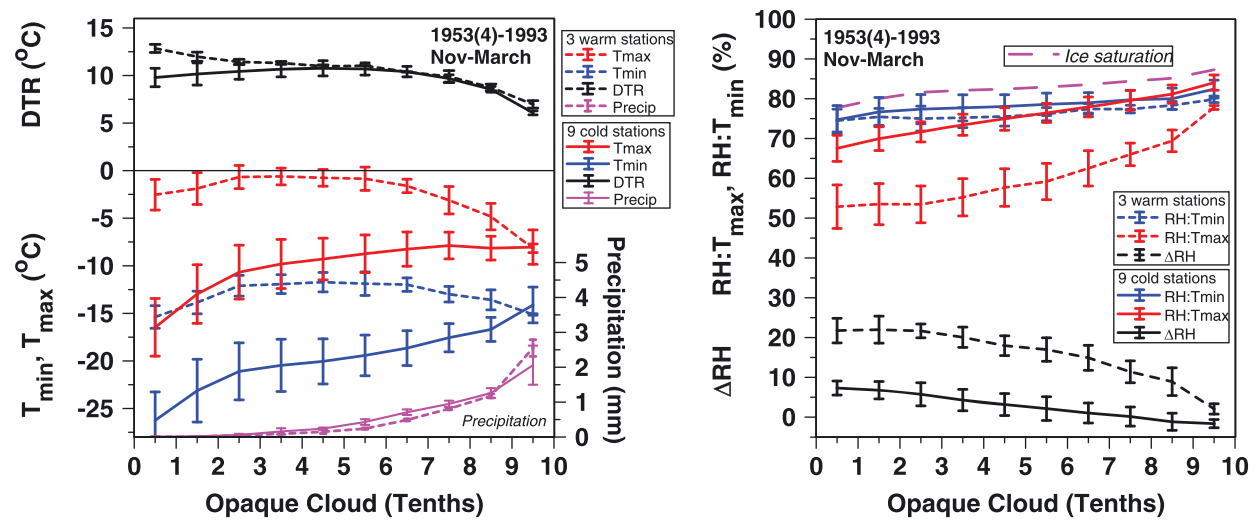

Figure 12. $T_{\max }, T_{\min }, D T R$, and precipitation (left panel) and (right panel) RH: $T_{\min }, R H: T_{\max }$, and $\Delta R H$ for two groups of climate stations in the cold season, November to March. 



Figure 13. Distributions of $\mathrm{T}_{\text {bias }}$ (left) and $\mathrm{RH}_{\text {bias }}$ (right) as a function of cloud cover for warm and cold periods and all data.

\section{Relation of Opaque Cloud Measurements to Surface Radiation Fields}

[56] This section quantifies the relationships between the opaque cloud observations and cloud radiative forcing using measurements of downward shortwave and longwave fluxes. $\mathrm{SW}_{\mathrm{dn}}$ is available at four Prairie stations (section 5.2), and $\mathrm{LW}_{\mathrm{dn}}$ is also available near two stations from the BOREAS and BERMS research experiments (section 5.3). Our goal is to provide fits that can be used to compute radiation fluxes from the opaque cloud data (section 5.4). Section 5.1 starts with some definitions.

\subsection{Surface Radiation Budget}

[57] The surface net radiation, $R_{\text {net }}$, can be expanded in terms of the net shortwave and longwave fluxes, $\mathrm{SW}_{\text {net }}$ and $\mathrm{LW}_{\text {net }}$ and their components, the upward and downward fluxes (suffices: up and dn)

$$
\mathrm{R}_{\text {net }}=\mathrm{SW}_{\text {net }}+\mathrm{LW}_{\text {net }}=\left(\mathrm{SW}_{\mathrm{dn}}-\mathrm{SW}_{\mathrm{up}}\right)+\left(\mathrm{LW}_{\mathrm{dn}}-\mathrm{LW}_{\mathrm{up}}\right)
$$

[58] Opaque clouds reduce the downward shortwave flux, $\mathrm{SW}_{\mathrm{dn}}$, below its clear-sky value, $\mathrm{SW}_{\mathrm{dn}}$ (clear).
This is expressed as the surface SWCF, defined negative as

$$
\mathrm{SWCF}=\mathrm{SW}_{\mathrm{dn}}-\mathrm{SW}_{\mathrm{dn}}(\text { clear })
$$

Betts and Viterbo [2005]; Betts [2009] defined an effective cloud albedo, ECA, as

$$
\mathrm{ECA}=-\mathrm{SWCF} / \mathrm{SW}_{\mathrm{dn}}(\text { clear})
$$

[59] This is a dimensionless measure of the fraction of $\mathrm{SW}_{\mathrm{dn}}$ (clear) that is reflected or absorbed by the cloud field per unit area of the surface. This removes the seasonal change in the clear-sky flux. The effective cloud albedo that plays a similar role to the surface albedo $\left(\alpha_{\mathrm{s}}\right)$ in the surface energy balance, since the net shortwave flux can be written as

$$
\mathrm{SW}_{\text {net }}=\left(1-\alpha_{\mathrm{s}}\right)(1-\mathrm{ECA}) \mathrm{SW}_{\mathrm{dn}}(\text { clear })
$$

where

$$
\alpha_{\mathrm{s}}=\mathrm{SW}_{\mathrm{up}} / \mathrm{SW}_{\mathrm{dn}}
$$

[60] In section 5.2, we will relate opaque cloud cover to this ECA.
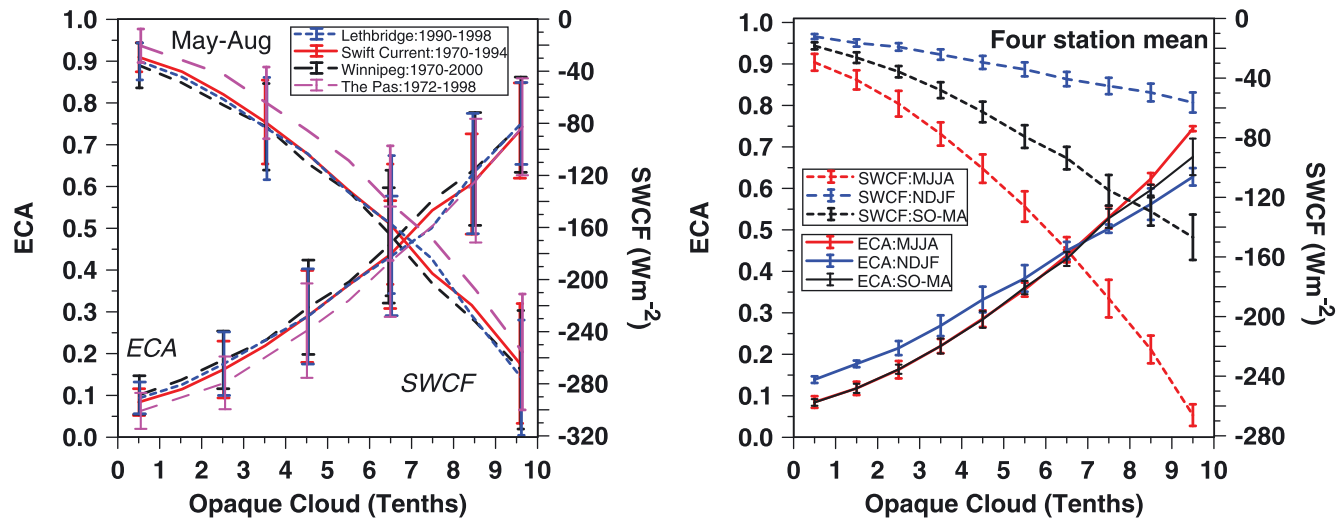

Figure 14. Relation between opaque cloud cover, ECA and SWCF for Lethbridge, Swift Current, Winnipeg, and The Pas for MJJA (left), and (right) mean ECA and SWCF of all data, for MJJA, NDJF, and SO-MA. 

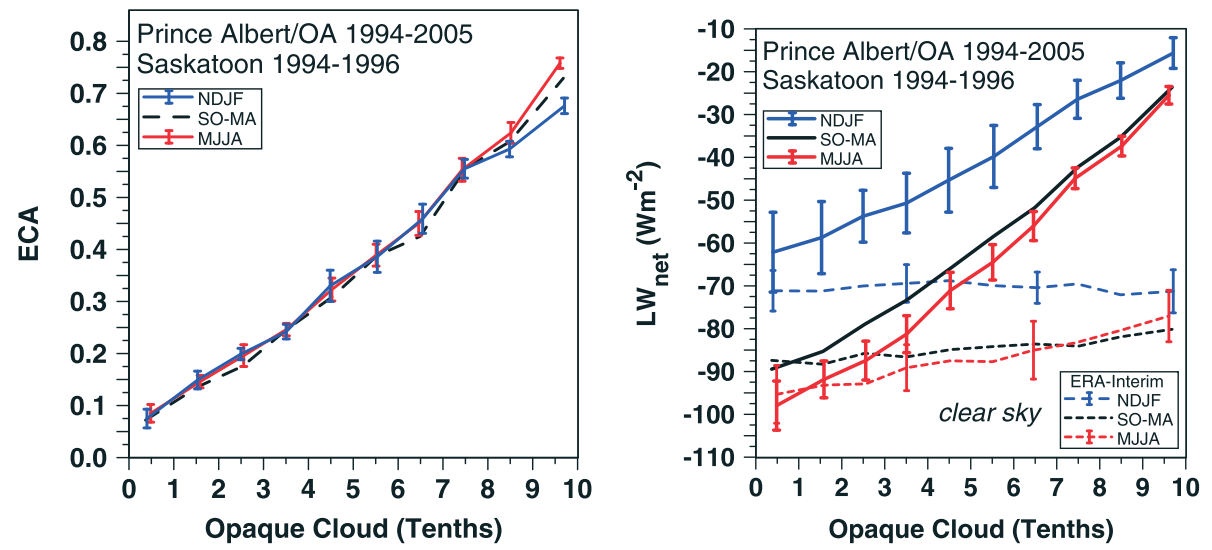

Figure 15. Relation between ECA and opaque cloud for merged Saskatoon and Prince Albert-Old Aspen data for MJJA, NDJF, and SO-MA (left) and (right) $\mathrm{LW}_{\text {net }}$ and $\mathrm{LW}_{\text {net }}($ clear).

[61] Opaque clouds also reduce the outgoing net longwave flux, giving a positive LWCF defined in terms of the net fluxes as

$$
\mathrm{LWCF}_{\mathrm{n}}=\mathrm{LW}_{\text {net }}-\mathrm{LW}_{\text {net }}(\text { clear })
$$

We have measurements of $\mathrm{LW}_{\mathrm{dn}}$ at two sites, and we will calculate an approximate $\mathrm{LW}_{\text {up }}$ from the climate station daily mean surface temperature as

$$
\mathrm{LW}_{\text {up }}=\sigma\left(273.15+\mathrm{T}_{\text {mean }}\right)^{4}
$$

where $\sigma=5.67 * 10^{-8}$ and the emissivity is set to 1 .

[62] The corresponding net SWCF

$$
\mathrm{SWCF}_{\mathrm{n}}=\left(1-\alpha_{\mathrm{s}}\right) \operatorname{SWCF}
$$

requires the surface albedo, which must be estimated or derived from $\mathrm{SW}_{\text {up. }}$. This is a significant issue in winter with snow cover (see section 5.3 later). We can then define the net cloud forcing, the impact of the clouds on $\mathrm{R}_{\text {net }}$, as

$$
\mathrm{CF}_{\mathrm{n}}=\mathrm{SWCF}_{\mathrm{n}}+\mathrm{LWCF}_{\mathrm{n}}=\mathrm{R}_{\text {net }}-\mathrm{R}_{\text {net }}(\text { clear })
$$

[63] We will use ERA-Interim for an estimate of $\mathrm{LW}_{\text {net }}$ (clear) at a grid point archived for BOREAS and BERMS. We estimated the clear-sky flux, $\mathrm{SW}_{\mathrm{dn}}$ (clear), by fitting an upper asymptote to the maximum daily values of $\mathrm{SW}_{\mathrm{dn}}$ : details are in the Appendix B. Our strategy is to calibrate the opaque cloud cover in the climate station data in terms of SWCF and $\mathrm{LWCF}_{\mathrm{n}}$, using measurements of $\mathrm{SW}_{\mathrm{dn}}$ and $\mathrm{LW}_{\mathrm{dn}}$.

\section{2. $\mathrm{SW}_{\mathrm{dn}}$ at Lethbridge, Swift Current, the Pas, and Winnipeg}

[64] We used the measured $\mathrm{SW}_{\mathrm{dn}}$ at four climate stations: Swift Current (1970-1994), The Pas (1972-1998), Winnipeg (1970-2000), and Lethbridge (1990-1998). For Swift Current, the period when nighttime data are missing was filtered out, leaving 1970 to May 1980, and June 1986 to 1994. The loss of the nighttime data does not affect ECA or SWCF, but it would introduce a small bias with respect to our other data which use daily mean opaque cloud (see Figure 4).

[65] We partition the year into three blocks by solar zenith angle: May to August (MJJA); November to February (NDJF), and the months, September, October, March, and April (SO-MA). Figure 14 (left panel) shows the warm season (MJJA) comparison. The four stations have the same monotonic relationship between daily mean opaque cloud and daily mean ECA, and the related SWCF, within the standard deviations of the daily data shown.

[66] Figure 14 (right panel) is the mean of the four stations partitioned into the three blocks of months. Note how small the standard deviations are across the four station means.
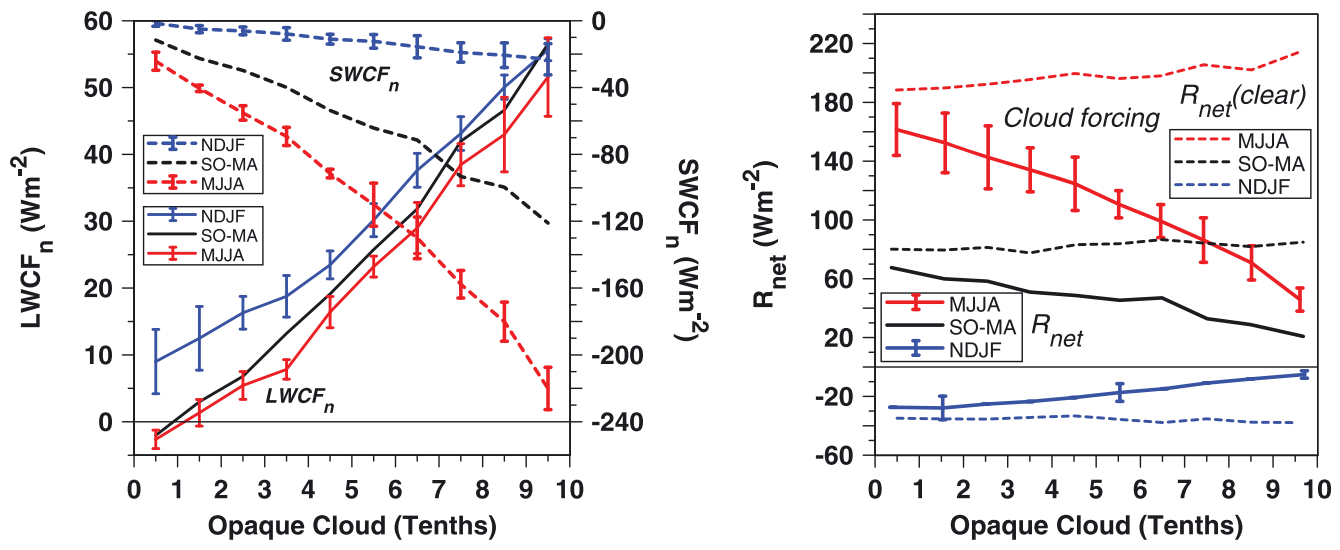

Figure 16. Relation between opaque cloud and $\mathrm{LWCF}_{n}$ and $\mathrm{SWCF}_{n}$ (left) and (right) $\mathrm{R}_{\text {net }}$ and $\mathrm{R}_{\text {net }}$ (clear) for merged Saskatoon and Prince Albert-Old Aspen data for MJJA, NDJF, and SO-MA. 


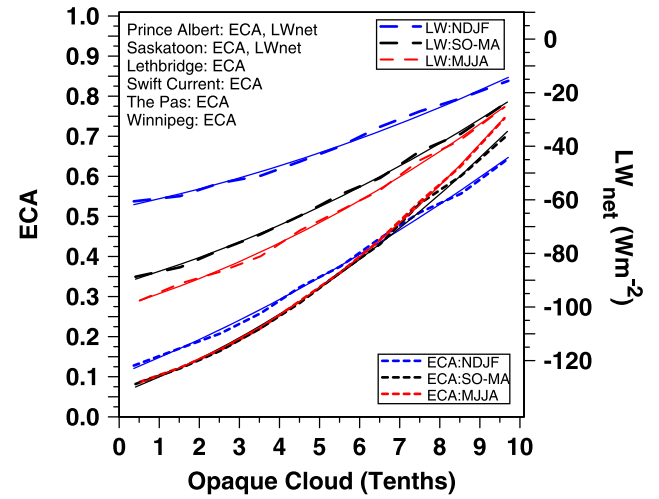

Figure 17. Relation between opaque cloud, ECA, and $\mathrm{LW}_{\text {net, }}$, with quadratic curve fits for NDJF, SO-MA, and MJJA (solid lines).

This confirms that the measurements of opaque cloud by trained observers appear to have little bias from station to station (see also Figure 2). The variation of SWCF reflects the changing solar zenith angle. The mean curves for ECA are almost identical for MJJA and SO-MA, but at high zenith angles in NDJF, the ECA dependence on opaque cloud is flatter. Note that in these climate composites, the upper limit of $\mathrm{ECA} \approx 0.8$ is comparable to the reflectivity of fresh snow, so that both clouds and snow play a comparable role in (9) in reducing $\mathrm{SW}_{\text {net }}$ in winter.

\section{3. $\quad \mathrm{SW}_{\mathrm{dn}}$ and $\mathbf{L W} \mathrm{W}_{\mathrm{dn}}$ at Saskatoon and Prince Albert}

[67] We used the daily mean $\mathrm{SW}_{\mathrm{dn}}$ and $\mathrm{LW}_{\mathrm{dn}}$ fluxes (see section 2.3) at Saskatoon $(8 \mathrm{~km}$ from the airport climate data), and the BOREAS/BERMS OA site at Prince Albert National Park $(57 \mathrm{~km}$ from the climate station at Prince Albert airport), as representative for these closest climate stations. Figure 2 showed good correlation of the daily mean opaque cloud data between Regina and Moose Jaw at a separation of $64 \mathrm{~km}$.

[68] Figure 15 (left panel) shows the relation of ECA to opaque cloud for these merged data, using the same partition of months as in Figure 14. As a measure of the variability on the monthly timescale, we show the standard deviation across the four monthly means contained in each average. For MJJA and SO-MA, the plots are almost identical to Figure 14 (right panel), but the NDJF plots show differences at low cloud cover, when the uncertainty in the ECA computation is largest, because the $\mathrm{SW}_{\mathrm{dn}}$ fluxes are small (see Appendix B).

[69] Figure 15 (right panel) shows the coupling between climate station opaque cloud and $\mathrm{LW}_{\text {net }}$ and $\mathrm{LW}_{\text {net }}$ (clear). $\mathrm{LW}_{\text {up }}$ was calculated from climate station $\mathrm{T}_{\text {mean }}$ using (11b). The clear sky fluxes come from ERA-Interim (see section 2.3). We again show the variability across the four monthly means within each average. The OA measurements are on the western edge of the ERA-Interim $80 \mathrm{~km}$ size grid box centered at $53.68^{\circ} \mathrm{N}, 105.56^{\circ} \mathrm{W}$, and the Prince Albert airport is on the southern edge of the grid box (Figure 1). However, Saskatoon is $184 \mathrm{~km}$ to the southsouth-west. The calculated clear-sky fluxes vary little on days with different cloud cover. Outgoing $\mathrm{LW}_{\text {net }}$ falls steeply with increasing opaque cloud, becoming small with overcast skies, as expected.
[70] The difference between each colored pair is the $\mathrm{LWCF}_{\mathrm{n}}$, shown in Figure 16 (left panel) along with the corresponding $\mathrm{SWCF}_{\mathrm{n}}$. The positive $\mathrm{LWCF}_{\mathrm{n}}$ is remarkably similar throughout the year, peaking at $55 \mathrm{Wm}^{-2}$ with overcast skies. The differences at low cloud cover and particularly the small negative values are not significant. The measurement accuracy for $\mathrm{LW}_{\mathrm{dn}}$ is $\pm 5 \mathrm{Wm}^{-2}$ [Betts et al., 2006], and our calculation of $\mathrm{LW}_{\text {up }}$ from (11b) differs from the reanalysis spatial and temporal integration based on the model surface temperature and emissivity. As in Figure 15, we show the variability across the four monthly means within each average.

[71] The $\mathrm{SWCF}_{\mathrm{n}}$ shows the same pattern as in Figure 15, but with smaller values since $\mathrm{SWCF}_{\mathrm{n}}=\left(1-\alpha_{\mathrm{s}}\right) \mathrm{SWCF}$ from (11b). For MJJA and SO-MA, we used the measured surface albedo, $\alpha_{\mathrm{s}}$, at both sites. For MJJA, these are $\alpha_{\mathrm{s}}=0.20 \pm 0.01$ for Saskatoon and $\alpha_{\mathrm{s}}=0.15 \pm 0.02$ for the OA forest. For SO-MA, with some intermittent snow cover, $\alpha_{\mathrm{s}}=0.29 \pm 0.18$ for Saskatoon and $\alpha_{\mathrm{s}}=0.17 \pm 0.04$ at OA. The differences here between grass and forest sites are significant, but uncertainty in $\alpha_{\mathrm{s}}$ plays only a small role in Figure 16 in either MJJA or SO-MA, when the SW fluxes dominate. At the Saskatoon site, we also used the NDJF measured surface albedo: where the mean of $\alpha_{\mathrm{s}}=0.70 \pm 0.30$ is high, because the measurements are over snow-covered grass. However, at the OA forest site for NDJF, mean $\alpha_{\mathrm{s}}=0.23 \pm 0.07$ is remarkably low, because the forest canopy shades the snow at high zenith angles. This low value for the boreal forest in winter [Betts and Ball, 1997] is not representative of the northern Prairies from Prince Albert south, so we replaced it with a nominal fixed NDJF albedo of $\alpha_{\mathrm{s}}=0.5$ for the merge of the Prince Albert and OA data.

[72] Figure 16 (right panel) shows the relation between opaque cloud and $R_{\text {net }}$ and $R_{\text {net }}$ (clear), where the difference is also the net cloud forcing, $\mathrm{CF}_{\mathrm{n}}$ (see (13)). For $\mathrm{R}_{\text {net }}$ (MJJA), we show the intermonth variability. The error bars on $R_{\text {net }}$ (NDJF) correspond to an uncertainty of \pm 0.15 in our specification of $\alpha_{\mathrm{s}}=0.5$.

[73] For MJJA and SO-MA, the SW fluxes dominate and $\left(-\mathrm{SWCF}_{\mathrm{n}}\right)>\mathrm{LWCF}_{\mathrm{n}}$. So $\mathrm{R}_{\text {net }}$ is positive and decreases with increasing cloud, since $\mathrm{CF}_{\mathrm{n}}$ becomes more negative with increasing opaque cloud. The complete reverse is true in NDJF, when the LW fluxes dominate and $(-\mathrm{SWCFn})<\mathrm{LWCFn}$. As a result, $\mathrm{R}_{\text {net }}$ is negative and becomes near zero with increasing cloud, since the positive $\mathrm{CF}_{\mathrm{n}}$ increases with increasing opaque cloud. This radical difference in cloud radiative forcing between warm and cold seasons will be compared with the difference in the diurnal cycle in section 6.1.

\subsection{Radiation Fits to Opaque Cloud Data}

[74] Figures 14 to 16 show that the relationship between opaque cloud cover and ECA has little variability from March to October across six different sites. Our more limited LW data from the BOREAS and BERMS also show rather little variability from March to October in $\mathrm{LW}_{\text {net }}$ and $L W C F_{n}$.

[75] Figure 17 gives a semiquantitative calibration of the measured opaque cloud cover in the climate station data in terms of ECA and $\mathrm{LW}_{\text {net }}$. For the ECA plots, we merged all the daily data from the four climate stations in section 5.2 with the Saskatoon and Prince Albert/OA merge in section 5.3 (about 90 station-years of data). The $\mathrm{LW}_{\text {net }}$ plots are simply the data from Figure 15 (right panel). 

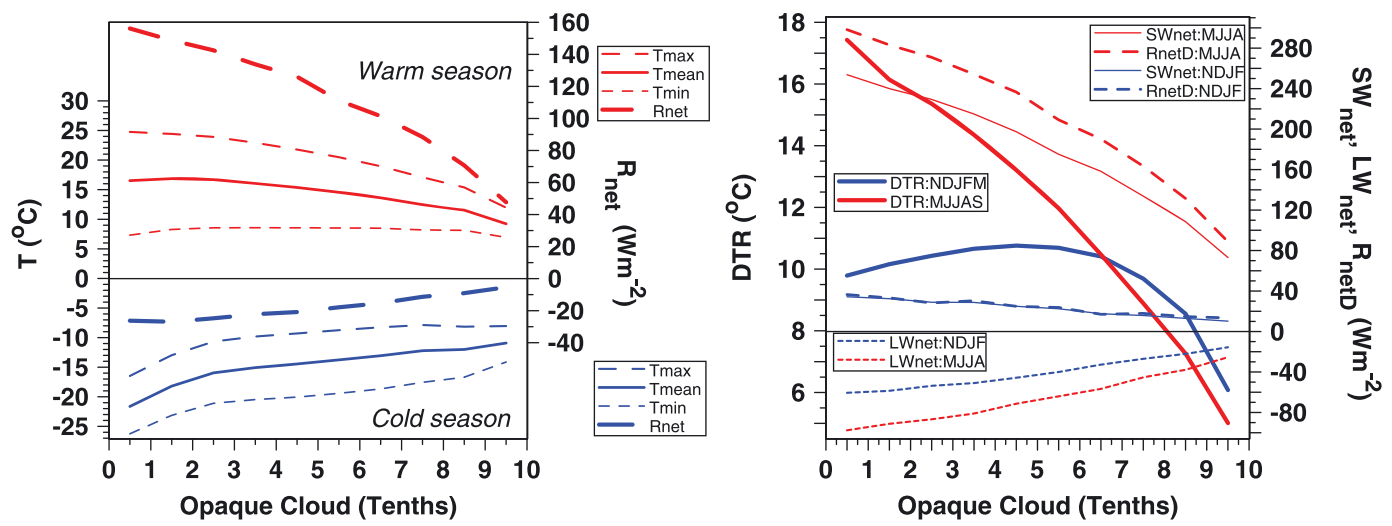

Figure 18. Relation between opaque cloud and (left) $\mathrm{R}_{\text {net }}, \mathrm{T}_{\max }, \mathrm{T}_{\min }$, and $\mathrm{T}_{\text {mean }}$ and (right) DTR and $\mathrm{SW}_{\text {net }}, \mathrm{LW}_{\text {net }}$ and $\mathrm{R}_{\text {netD }}$, a daytime mean, for warm and cold seasons.

[76] The solid lines are the quadratic fits to the data. For ECA, they are

$$
\begin{aligned}
& \text { NDJF }: \text { ECAfit }=0.1056+0.0404 \text { OpaqueCloud } \\
& +0.00158 \text { OpaqueCloud }^{2} \\
& \text { SO-MA }: \text { ECAfit }=0.0588+0.0365 \text { OpaqueCloud } \\
& +0.00318 \text { OpaqueCloud }^{2} \\
& \text { MJJA }: \text { ECAfit }=0.0681+0.0293 \text { OpaqueCloud } \\
& +0.00428 \text { OpaqueCloud }^{2}
\end{aligned}
$$

[77] Note that these fits do not go to zero when opaque cloud is zero, as there may be some thin clouds reducing atmospheric transmission. Another reason is a limitation of our daily mean analysis. Opaque cloud is a daily mean, but ECA is a daytime mean weighted by the solar flux, so that increased daytime cloud (see Figure 4) will associate higher values of ECA with lower daily mean cloud cover. In addition, our fits (B1) to $\mathrm{SW}_{\mathrm{dn}}$ (clear) do not account for variations in atmospheric humidity. The $\mathrm{SW}_{\text {net }}$ can be calculated from (9) using (14) and section (B2) for $\mathrm{SW}_{\mathrm{dn}}$ (clear), if surface albedo, $\alpha_{\mathrm{s}}$, is known or can be estimated.

[78] For $\mathrm{LW}_{\text {net }}$, they are

$$
\begin{aligned}
\text { NDJF : } \mathrm{LW}_{\text {net }}= & -63.0+3.14 \text { OpaqueCloud } \\
& +0.193 \text { OpaqueCloud }^{2} \\
\text { SO-MA : } \mathrm{LW}_{\text {net }}= & -91.5+4.43 \text { OpaqueCloud } \\
& +0.267 \text { OpaqueCloud } \\
\text { MJJA : } \mathrm{LW}_{\text {net }}=- & 100.1+4.73 \text { OpaqueCloud }^{2} \\
+ & 0.317 \text { OpaqueCloud }
\end{aligned}
$$

[79] The quadratic fits (14) and (15) fit the mean data very closely. However, the true uncertainty is hard to assess. The standard deviations of the daily ECA data for each station, shown in Figure 14 (left panel), are of order 0.1, but the standard deviations across the four station means of ECA in Figure 14 or the intermonth differences in Figure 15 are much smaller, of the order of $0.02-0.03$. Figure 15 also shows that the variability of the monthly $\mathrm{LW}_{\text {net }}$ is of the order of \pm 5 to $10 \mathrm{Wm}^{-2}$ in warm and cold seasons. The standard deviations of the daily $\mathrm{LW}_{\text {net }}$ (not shown) are larger, of the order of $\pm 15 \mathrm{Wm}^{-2}$.
[80] The different slope of the ECA-opaque cloud relation in winter could be the impact of high solar zenith angle on either the visual opaque cloud observations, or the SW transmission, or the different optical properties of summer and winter clouds. We estimate the uncertainty in our fits (section (B2)) for $\mathrm{SW}_{\mathrm{dn}}$ (clear) to be about $\pm 7 \mathrm{Wm}^{-2}$, and this means the computation of ECA is also most sensitive in winter when $\mathrm{SW}$ fluxes are low. In addition, our fits to $\mathrm{SW}_{\mathrm{dn}}$ (clear) do not include day-to-day variations associated with changing atmospheric water vapor and aerosols.

[81] Nonetheless, the fits (14) and (15) provide a useful basis for converting the opaque cloud observations into net radiative fluxes, and cloud radiative forcing.

\section{Synthesis}

[82] In section 6.1, we put together the different components of our analysis: the reduced diurnal data set for the Prairie climate stations from section 4.1, and the relation between cloud cover, LW and SW radiation fluxes from section 5 . This will show the radically different cloud radiative forcing of the diurnal cycle climate in the warm and cold seasons. In section 6.2, we will discuss the day and nighttime radiative drivers of the diurnal cycle, and in section 6.3, we show that DTR, $\triangle \mathrm{RH}$, and the radiative fluxes have a quasi-linear dependence on ECA.

\subsection{Relating Diurnal Cycle of Temperature and Radiative Forcing}

[83] Figure 18 (left panel) combines the warm (MJJA) and cold (NDJF) season $R_{\text {net }}$ from Figure 16 with the $T_{\max }, T_{\min }$ (and $\mathrm{T}_{\text {mean }}$ ) for MJJAS for the Prairie data in Figure 11 and NDJFM from Figure 12 (cold group of nine stations). Note that the monthly groups that we selected for temperature include one later month than the radiative forcing groups, reflecting in part the seasonal lag in land-surface temperatures, but this difference is not significant here.

[84] The large seasonal cycle of temperature is of course driven by the positive net radiative forcing in the warm season and the negative net radiative forcing in the cold season. As cloud decreases in the warm season, the $\mathrm{SWCF}_{\mathrm{n}}$ dominates, and $T_{\max }$ increases with $\mathrm{R}_{\text {net }}$ while $\mathrm{T}_{\min }$ is nearly flat. In contrast, as cloud decreases in winter, the $\mathrm{LWCF}_{\mathrm{n}}$ dominates, and both $\mathrm{T}_{\max }$ and $\mathrm{T}_{\min }$ fall with clearer skies. 




Figure 19. Relation between DTR and $\mathrm{LW}_{\text {net }}$ (bottom scale) and $R_{\text {netD }}$ (top scale) for April to August.

[85] Figure 18 (right panel) shows the cloud dependence of DTR (left axis) and (right axis) $\mathrm{SW}_{\text {net }}, \mathrm{LW}_{\text {net }}$, and $\mathrm{R}_{\text {netD, }}$, daytime mean that is driving the daytime rise of temperature (see section (B2)). In the warm season, the steep rise of DTR with decreasing cloud is related to the corresponding steep rise of $R_{\text {netD }}$ (see section 6.2).

[86] In the cold season, the diurnally averaged $R_{\text {net }}$ is negative, reaching a maximum negative value of $-26 \mathrm{Wm}^{-2}$ when cloud cover is small. However, the short day length $\approx 9 \mathrm{~h}$, means that $\mathrm{SW}_{\mathrm{dnD}} \approx 2.8 \mathrm{SW}_{\mathrm{dn}}$ while $\mathrm{LW}_{\text {netD }} \approx \mathrm{LW}_{\text {net. }}$. As a result, daytime mean $R_{\text {netD }}$ is positive for NDJF, reaching a maximum value, when cloud cover is small, of $+36 \mathrm{Wm}^{-2}$, almost identical to daily mean $\mathrm{SW}_{\text {net }}$. It is again $\mathrm{R}_{\text {netD }}$ that drives the daytime rise of temperature. However, we have no simple radiative explanation for the curved shape of DTR with a maximum near $50 \%$ opaque cloud cover. The structure of the shallow winter stable BLs probably plays a role in the diurnal range of temperature. The warm season $\mathrm{BL}$, unstable in the daytime, is usually coupled to a deep convective BL, but in winter under clear skies, a shallow stable BL may persist through the daytime and simply get stronger at night.

\subsection{Radiative Drivers of Daytime Rise and Nighttime Fall of Temperature}

[87] Betts [2004, 2006] used reanalysis data to show that DTR and the strength of the nocturnal BL were both related to the daily mean $\mathrm{LW}_{\text {net }}$ in the tropics, and in the warm season at high northern latitudes. The conceptual model was that the fall of surface temperature from the afternoon maximum was driven by the LW cooling. We can extend this concept by noting that in the diurnal cycle climate, DTR must simultaneously satisfy two relationships:

[88] 1. the daytime rise from $T_{\min }$ to $T_{\max }$, coupled to $R_{\text {netD }}$ and sensible heat flux, $\mathrm{H}$

[89] 2. The evening and nighttime fall from $T_{\max }$ to $T_{\min }$, coupled to $\mathrm{LW}_{\text {net }}$.

[90] Figure 19 shows climate station DTR from Prince Albert and Saskatoon plotted against binned $\mathrm{LW}_{\text {net }}$ (bottom scale) and $R_{\text {netD }}$ (top scale) for the merged data sets in section 5.3. The relationships are similar, as both the rise of $R_{\text {netD }}$ and the increasing negative values for $L_{\text {net }}$ are coupled to a decrease of opaque cloud (Figures 16 and 18).
We show the mean of the five months symmetric about the summer solstice and the standard deviations of these five monthly means.

[91] Figure 19 supports the analysis of Betts [2006], who showed a quasi-linear relation between DTR and $\mathrm{LW}_{\text {net }}$ in the warm season using reanalysis data averaged over river basins. The flattening of the rise of DTR with increasing $\mathrm{R}_{\text {netD }}$ may reflect the fact that deeper BLs under stronger forcing may warm more slowly. Figure 19 shows that daytime and nighttime radiative processes can both be considered as drivers of the DTR. In these data for the coupled BL over land, both are satisfied in the diurnal cycle climate. In the warm season diurnal cycle, stronger SW forcing drives a deeper and drier afternoon BL, with a larger DTR and $\triangle \mathrm{RH}$, and a higher afternoon cloud base capping the mixed layer. This deeper layer with a dry adiabatic lapse rate up to cloud base, which is left as a residual layer after sunset, will in turn give larger outgoing $\mathrm{LW}_{\text {net }}$.

[92] In the warm season, the partition of the daytime net flux $R_{\text {netD }}$, into the latent heat $(\lambda E)$ and sensible heat $(H)$ fluxes and the ground storage $(\mathrm{G})$, is central to the surface energy balance, and the growth of the daytime BL.

$$
\mathrm{R}_{\text {netD }}=\lambda \mathrm{E}+\mathrm{H}+\mathrm{G}
$$

[93] If we neglect the small ground storage, the partition can be represented by the Bowen Ratio

$$
\mathrm{BR}=\mathrm{H} / \lambda \mathrm{E}
$$

[94] The Bowen Ratio depends on the availability of water, surface vegetation, and on land use, and it is $\mathrm{H}$ that is most closely coupled to the warming of the surface. Since we have no direct measurements of BR at the climate stations, we

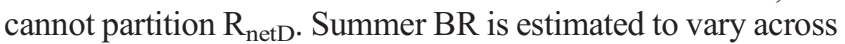
the Prairies in the range 0.5 to 1.9 [Shrestha et al., 2012]. This means that the warm season dependence of the mean BR on opaque cloud is an important unknown in our analysis that is implicitly coupled. Since precipitation increases steeply with opaque cloud in the warm season (Figure 11), BR will also fall with increasing cloud cover [Betts et al., 2007]. We will address these issues in a following paper.

\subsection{Quasi-Linear Dependence of DTR, $\Delta R H$, and Radiative Fluxes on Effective Cloud Albedo}

[95] Our analysis has been based on stratifying $\mathrm{T}$ and $\mathrm{RH}$ using observed opaque cloud cover, because this was available at all the climate stations. In section 5, we developed (14) and (15) to relate opaque cloud cover to ECA and $\mathrm{LW}_{\text {net }}$. Using the subset of four climate stations, Lethbridge, Swift Current, The Pas, and Winnipeg, which measured $\mathrm{SW}_{\mathrm{dn}}$, together with $\mathrm{LW}_{\text {net }}$ from (15), we can remap the diurnal cycle and the radiative fluxes that are driving the diurnal cycle directly onto ECA.

[96] Figure 20 (left panel) shows the mean diurnal cycle parameters for the four climate stations: the standard deviations across these stations in MJJA are rather small. We see that DTR, $\triangle \mathrm{RH}$, and $\mathrm{RH}_{\text {mean }}$ have a quasi-linear dependence on ECA. $\mathrm{T}_{\max }$ and $\mathrm{T}_{\text {mean }}$ increase with decreasing ECA, while $\mathrm{T}_{\text {min }}$ (not shown) is nearly flat $\approx 9.5^{\circ} \mathrm{C}$. The right panel shows that all the net radiative fluxes also have a quasi-linear dependence on ECA, as noted in Betts [2007] 

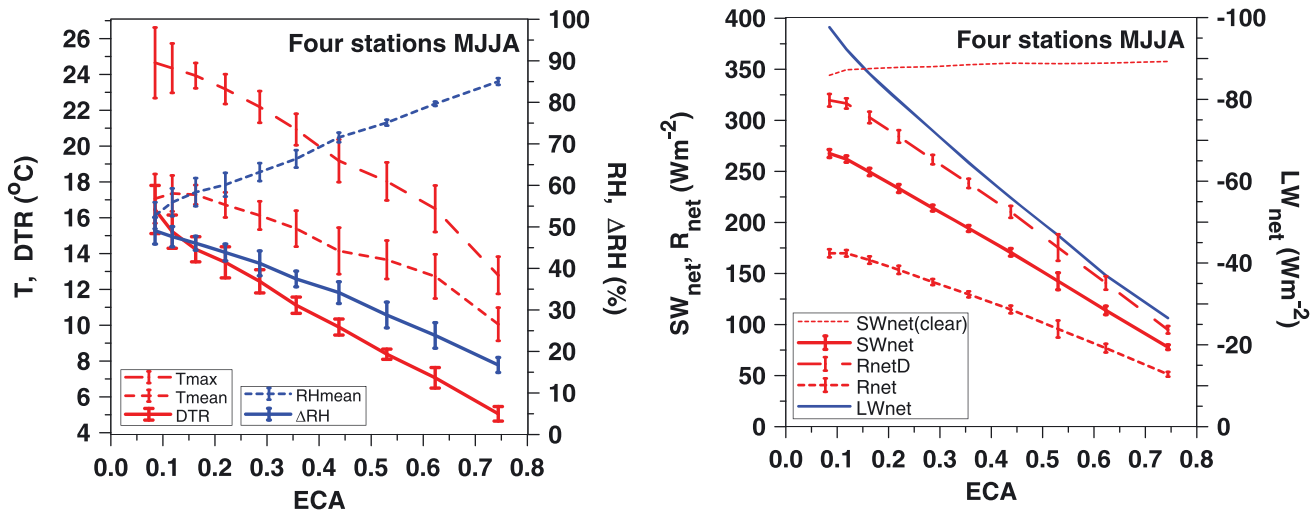

Figure 20. Relation between $\mathrm{T}_{\text {max }}, \mathrm{T}_{\text {mean }}, \mathrm{DTR}, \mathrm{RH}_{\text {mean }}$, and $\Delta \mathrm{RH}$ (left) and (right) $\mathrm{SW}_{\mathrm{dn}}$ (clear), $\mathrm{SW}_{\text {net }}$, $\mathrm{R}_{\text {netD }}, \mathrm{R}_{\text {net }}, \mathrm{LW}_{\text {net }}$ to ECA.

using reanalysis data. For $\mathrm{SW}_{\text {net }}$, this is essentially trivial, because $\mathrm{SW}_{\mathrm{dn}}$ (clear), computed using (B1a) and (B1b), has little variation, and the SWCF is linear in ECA by definition (8). We set $\alpha_{\mathrm{S}}=0.15$ in (9), a nominal summer value for the Prairies.

[97] $\mathrm{LW}_{\text {net }}$, which is plotted on a much expanded scale, and has no standard deviations because it is computed from (15), is also quasi-linear in ECA. This means that $R_{\text {net }}$ and the daytime mean $R_{\text {netD }}$ from (B2) are as well.

[98] Figure 20 summarizes how cloud reflectivity, represented by ECA, is the primary control on the net surface radiative fluxes, which in turn are drivers of the diurnal cycle of temperature and humidity over the Canadian Prairies in the warm season. Much of the opaque reflective cloud has roots in the BL in the warm season (Figure 8), so Figure 20 also relates to the warm season coupling between BL cloud, the surface SWCF, and the diurnal cycle. The one important aspect of the land-surface coupling that we are not addressing in these long data sets is again the variability of the surface BR, which depends on the seasonal cycle of surface vegetation and the availability of water.

\section{Conclusions}

[99] We have shown how the radiative forcing by clouds changes the diurnal cycle climate over the annual cycle. We used four decades of hourly observations of T, RH, and opaque cloud cover from 14 climate stations across the Canadian Prairies, to characterize the annual cycle of the diurnal cycle in terms of a reduced daily climate data set: $T_{\max }, T_{\min }$, $\mathrm{T}_{\text {mean }}$, and $\mathrm{RH}_{\text {mean }}$ and their diurnal ranges, DTR and $\Delta \mathrm{RH}$.

[100] The diurnal cycle climate has a common structure across the Prairies in the warm snow-free season from April to October, when shortwave fluxes dominate over longwave cooling. We found that

[101] 1. Warm season $T_{\max }$ and $T_{\text {mean }}$ decrease with increasing opaque cloud cover, but $\mathrm{T}_{\text {min }}$ does not.

[102] 2. The diurnal ranges, DTR and $\Delta \mathrm{RH}$, are tightly coupled to cloud cover, and both increase monotonically as cloud decreases.

[103] 3. Increasing cloud cover is tightly coupled to increasing $\mathrm{RH}$ and decreasing afternoon LCL, as well as increasing daily precipitation.

[104] The diurnal cycle climate has two distinct states: one in the warmer months when temperatures are above freezing, and a second in winter. For Regina, the rapid transition between these two states occurs in March and November, when $T_{\text {mean }}$ is below freezing and the ground is mostly snow covered. In winter (DJF), both maximum and minimum temperatures fall with decreasing opaque cloud, as LW cooling dominates over the net $\mathrm{SW}$ flux and $\Delta \mathrm{RH}$ becomes $\leq 5 \%$.

[105] This winter climate transition [Betts, 2011] often occurs rapidly with the first lasting snowfall, typically in November; when over three days, $\mathrm{T}_{\max }$ falls about $8^{\circ} \mathrm{C}$ and $\triangle \mathrm{RH}$ becomes small. The much higher albedo of the snow greatly reduces the surface $\mathrm{SW}_{\text {net }}$. The sublimation from the frozen surface is much less than the evaporation in earlier warmer months. On regional scales, tropospheric water vapor falls, and this increases the outgoing net longwave. In essence, the water vapor greenhouse effect is reduced. The snow cover also partially insulates and uncouples the ground from the atmosphere. All three processes cause the surface air temperature to fall with snow cover. The rapid transition in March is the reverse, as the surface and atmosphere warm in response to the decreasing solar zenith angle. As $\mathrm{T}_{\max }$ rises above zero, the snow melts, and surface evaporation from the wet ground increases steeply.

[106] We linked the daily mean opaque cloud cover to the LWCF and SWCF and the effective cloud albedo, using multiyear measurements of downward shortwave and longwave fluxes. We fitted the annual cycle of $\mathrm{SW}_{\mathrm{dn}}$ (clear) as an upper boundary to multiyear daily mean $\mathrm{SW}_{\mathrm{dn}}$ data and used a nearly colocated data set for $\mathrm{LW}_{\text {net }}$ (clear) from ERA-Interim. We estimated $\mathrm{LW}_{\text {up }}$ from $\mathrm{T}_{\text {mean }}$. We generated quadratic fits to compute effective cloud albedo and net longwave fluxes by season from opaque cloud cover. Collectively, this gives a semiquantitative calibration of the measured opaque cloud cover to the net radiative fluxes and the cloud forcing terms. Some uncertainties in cold season surface albedo with snow remain.

[107] We compared the seasonal diurnal cycle with the changes in the cloud-coupled radiative fluxes. The large seasonal cycle of temperature is of course driven by the positive net radiative forcing in the warm season and the negative net radiative forcing in the cold season. As cloud decreases in the warm season, the $\mathrm{SWCF}_{\mathrm{n}}$ dominates, and $\mathrm{T}_{\max }$ and DTR increase, while $T_{\min }$ is nearly flat. As cloud decreases in winter, the $\mathrm{LWCF}_{\mathrm{n}}$ dominates, and both $\mathrm{T}_{\max }$ and $\mathrm{T}_{\min }$ fall with clearer skies. However, these radiative arguments do not explain the cloud dependence of the DTR profile in 
winter with a maximum near $50 \%$ opaque cloud cover. The structure of the shallow winter stable BLs probably plays a role in the diurnal range of temperature. Under clear skies, a shallow stable BL may persist through the daytime and simply get stronger at night. In contrast, the warm season $\mathrm{BL}$, unstable in the daytime, is usually coupled to a deep convective BL.

[108] We examined the radiative drivers of the daytime rise and nighttime fall of temperature. Betts [2006] used reanalysis data, averaged over river basin scales, to show that DTR had a quasi-linear relationship to the daily mean $\mathrm{LW}_{\text {net }}$, both in the tropics and the warm season at high northern latitudes. We confirmed and extended this conceptual model by showing that in the warm season diurnal cycle climate, DTR satisfies two relationships simultaneously:

[109] 1. The daytime rise from $T_{\min }$ to $T_{\max }$ is coupled to $\mathrm{R}_{\text {netD. }}$.

[110] 2. The evening and nighttime fall from $T_{\max }$ to $T_{\min }$ is coupled to $\mathrm{LW}_{\text {net. }}$.

[111] In the warm season land-surface-BL-cloud system, stronger SW forcing drives a deeper and drier afternoon $\mathrm{BL}$, with a larger DTR and $\triangle \mathrm{RH}$, and a higher afternoon cloud base. This deeper and drier adiabatic layer with a steep lapse rate up to cloud base, which is left as a residual layer after sunset, will in turn give larger outgoing $\mathrm{LW}_{\text {net }}[\mathrm{e} . \mathrm{g}$., Betts and Chiu, 2010].

[112] We showed that in the warm season, DTR, $\Delta \mathrm{RH}$, and $\mathrm{RH}_{\text {mean }}$, and all the net radiative fluxes driving the diurnal cycle, have a quasi-linear dependence on the effective cloud albedo, as suggested by earlier model studies [Betts, 2007]. This clearly summarizes how cloud cover, represented quantitatively by ECA, is the primary control on the net surface radiative fluxes, which in turn drive the diurnal cycle of temperature and humidity in the warm season. The fact that the radiative drivers of the diurnal cycle depend on just the cloud cover is of fundamental importance. We will show in a following paper that this means that the stratification of the data by cloud (as in Figure 11) can be used to separate the radiative forcing of the land-surface from the surface energy partition, represented by the BR, which depends on soil moisture, land use, and temperature.

[113] The qualitative impacts of cloud on the diurnal cycle are familiar. This analysis provides a quantitative seasonal climate framework for understanding the impact of clouds and their radiative fluxes on the diurnal cycle of $\mathrm{T}, \mathrm{RH}$, cloud cover, and LCL. We used data from the Canadian Prairies, but it is likely that our results will have general applicability at northern latitudes, as they show the importance of the sharp winter transitions in snowy climates. We hope that this analysis will contribute to the improved representation of the land-surface-BL-cloud coupling in many types of models and encourage the inclusion of $\mathrm{RH}$ and cloud cover in longterm climate records.

[114] We chose the period from 1953 to 1993 to couple the cloud radiative forcing to the diurnal cycle climate over the seasonal cycle. In recent decades, the global climate has generally been warming primarily as a result of anthropogenic greenhouse gas emissions, amplified by water vapor feedback. In addition, snow-ice albedo feedback has accelerated the warming and melting of the Arctic sea-ice in summer and the warming of midlatitudes in winter. Within this broad global context, agricultural regions of Canada have been experiencing a warming climate. This has resulted in an increase in the length of the growing season and in effective growing degree days [Qian et al., 2009, 2012] and in substantial reductions in winter severity across the entire North American continent [Krakauer, 2012]. Our diurnal cycle analysis in terms of cloud radiative forcing does not address these climate change issues.

[115] In addition, these long-term climate records have no direct data on the variability of the surface Bowen ratio, which depends on surface vegetation and the availability of water. In the past 30 years, there has been a major change in land use, specifically the conversion of more than five million hectares of summerfallow to continuous cropping. This has modified the warm season climate over the Prairies [Gameda et al., 2007]. Increased summer transpiration has been associated with a decrease in mean daily maximum temperature and the diurnal temperature range, a decrease in the incoming solar radiation, and an increase in precipitation, particularly during mid-July at the peak of the growing season. We will explore this coupling between climate change, land use, surface Bowen ratio, cloud cover, and the summer diurnal cycle climate in a subsequent paper.

\section{Appendix A: Thermodynamic Formulae}

[116] We derived the mixing ratio (Q), the pressure height to the LCL $\left(\mathrm{P}_{\mathrm{LCL}}\right)$, and the equivalent potential temperature $\left(\theta_{\mathrm{E}}\right)$ from climate station air pressure $(\mathrm{p}$ in $\mathrm{hPa})$, dry bulb temperature ( $\mathrm{T}$ in ${ }^{\circ} \mathrm{C}$ ), $\mathrm{RH}$ (in \%) with respect to water saturation, We used Teton's formula for water saturation vapor pressure ES (in $\mathrm{hPa}$ )

$$
\mathrm{ES}(\text { water })=6.1078 * \operatorname{EXP}(17.269 * \mathrm{~T} /(237.3+\mathrm{T}))
$$

For ice saturation, we used

$$
\mathrm{ES}(\text { ice })=6.1078 * \operatorname{EXP}(21.875 * \mathrm{~T} /(265.5+\mathrm{T}))
$$

[117] Then vapor pressure, e, (in $\mathrm{hPa}), \mathrm{Q}(\mathrm{g} / \mathrm{kg})$ and potential temperature $(\theta$ in $\mathrm{K})$ are given by

$$
\begin{gathered}
\mathrm{e}=(\mathrm{RH} / 100) * \mathrm{ES} \\
\mathrm{Q}=622 * \mathrm{e} /(\mathrm{p}-\mathrm{e}) \\
\theta=(\mathrm{T}+273.15) *(1000 / \mathrm{p})^{0.286}
\end{gathered}
$$

[118] We derived saturation temperature (Tsat) at the LCL using Bolton [1980] and the corresponding saturation pressure (Psat) and $\mathrm{P}_{\mathrm{LCL}}$ from

Tsat $=55+(2840 /(3.5 * \operatorname{LN}(\theta)-\operatorname{LN}(1000 * \mathrm{q} /(622+\mathrm{q}))-4.805)))$

$$
\begin{gathered}
\text { Psat } \left.=1000 *(\text { Tsat } / \theta)^{\wedge} 3.4965\right) \\
P_{\mathrm{LCL}}=\mathrm{p}-\text { Psat }
\end{gathered}
$$

[119] The LCL height was computed from $\mathrm{P}_{\mathrm{LCL}}$ using a mean density for the layer. For $\theta_{\mathrm{E}}$, we used [Betts, 1982]

$$
\theta_{\mathrm{E}}=\theta \exp (2.67 * \mathrm{Q} / \text { Tsat })
$$




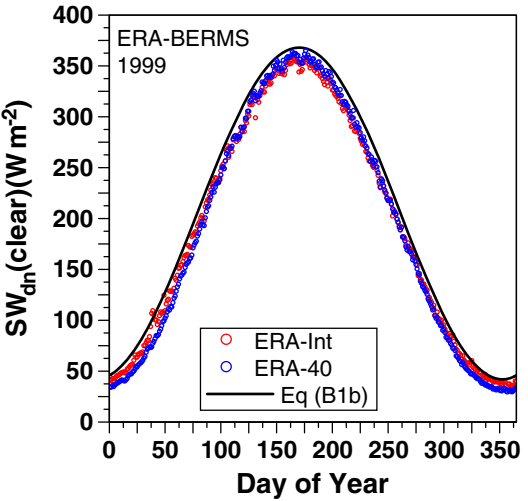

Figure B1. Comparison of $\mathrm{SW}_{\mathrm{dn}}$ (clear) estimates.

\section{Appendix B: Estimation of Clear-Sky Shortwave Flux and Daytime $\mathbf{R}_{\text {netD }}$}

\section{B1. Clear-Sky Shortwave Flux}

[120] We estimated the clear-sky flux, $\mathrm{SW}_{\mathrm{dn}}$ (clear), by fitting an upper asymptote to the maximum daily values of $\mathrm{SW}_{\mathrm{dn}}$. We used the same fit for all three southern stations, Lethbridge at $49.63^{\circ} \mathrm{N}$; Swift Current at $50.3^{\circ} \mathrm{N}$, and Winnipeg at $49.82^{\circ} \mathrm{N}$

$\mathrm{SW}_{\mathrm{dn}}($ clear $\left.\left.)=\mathrm{SW}_{\mathrm{dn}}(\max )=68+321 * \operatorname{COS}(\mathrm{PI} * \mathrm{DOY}-170) / 365\right)\right)^{2}$

For The Pas at higher latitude, $53.97^{\circ} \mathrm{N}$, we used the fit

$\mathrm{SW}_{\mathrm{dn}}($ clear $\left.)=\mathrm{SW}_{\mathrm{dn}}(\max )=42+326^{*} \mathrm{COS}(\mathrm{PI} * \mathrm{DOY}-170) / 365\right)^{2}$

At Saskatoon $\left(52.16^{\circ} \mathrm{N}\right)$, we used

$\mathrm{SW}_{\mathrm{dn}}($ clear $\left.)=\mathrm{SW}_{\mathrm{dn}}(\max )=54+324 * \operatorname{COS}\left(\mathrm{PI}{ }^{*} \mathrm{DOY}-170\right) / 365\right)^{2}$

For the BOREAS site at OA site $\left(53.63^{\circ} \mathrm{N}\right)$, we used

$\mathrm{SW}_{\mathrm{dn}}($ clear $\left.)=\mathrm{SW}_{\mathrm{dn}}(\max )=44+325^{*} \mathrm{COS}(\mathrm{PI} * \mathrm{DOY}-170) / 365\right)^{2}$

[121] SWCF and ECA were then computed from (7) and (8).

[122] Hourly clear-sky flux calculations from the two reanalyses, ERA-40 and ERA-Interim, for a grid point at $53.68^{\circ} \mathrm{N}, 105.56^{\circ} \mathrm{W}$, were archived as a special product for BOREAS and BERMS (Martin Köhler, personal communication). Figure B1 compares the daily mean values of the computed $\mathrm{SW}_{\mathrm{dn}}$ (clear) from the two reanalyses with $(\mathrm{B} 1 \mathrm{~b})$, our fit for The Pas at $53.97^{\circ} \mathrm{N}$, $101.1^{\circ} \mathrm{W}$. The two reanalyses have different humidity analyses, different aerosol assumptions, and differences in their radiative codes, which result in the clear-sky flux calculations from ERA-Interim being higher than ERA-40 in winter by about $+7 \mathrm{Wm}^{-2}$ and lower in summer by a similar amount. The fixed fit (B1b) for The Pas is slightly higher than both reanalyses and has of course none of the day-to-day variability.
[123] From these comparisons, we estimate the uncertainty in our fits (B1) for $\mathrm{SW}_{\mathrm{dn}}$ (clear) to be about $\pm 7 \mathrm{Wm}^{-2}$. This corresponds to a rather small uncertainty in ECA in summer of the order of \pm 0.02 , but a much larger uncertainty in ECA in winter of the order of \pm 0.1 . Measurement accuracy in $\mathrm{SW}_{\mathrm{dn}}$ is probably also of the order of $\pm 5 \mathrm{Wm}^{-2}$. Betts et al. [2006] noted similar discrepancies between the ERA-40 $\mathrm{SW}_{\mathrm{dn}}$ (clear) and the BERMS measurements and derived a corrected fit for $\mathrm{SW}_{\mathrm{dn}}$ (clear) for these data, which were included in our preprocessed BERMS data set.

\section{B2. Daytime $\mathbf{R}_{\text {netD }}$}

[124] Our basic data sets are daily means of $\mathrm{SW}_{\text {net }}$ and $\mathrm{LW}_{\text {net }}$. We estimated daytime $\mathrm{R}_{\text {net }}$ as

$$
\mathrm{R}_{\text {netD }}=\text { Daywt }^{*} \mathrm{SW}_{\text {net }}+\mathrm{LW}_{\text {net }}
$$

[125] The factor Daywt is the ratio of the mean over the daytime hours to the daily mean. We derived a monthly mean Daywt from 30 min data at Saskatoon and the OA site, defining daytime as $\mathrm{SW}_{\mathrm{dn}}>5 \mathrm{Wm}^{-2}$, and used the average of these almost identical monthly weights in (B2). The difference between daytime, nighttime, and daily mean $\mathrm{LW}_{\text {net }}$ is $<5 \%$ and was neglected.

[126] Acknowledgments. This research was supported by Agriculture and Agri-Food Canada, and by Atmospheric Research. This paper is dedicated to civilian and military technicians of the Meteorological Service of Canada and of the Canadian Forces Weather Service who have made accurate cloud observations hourly for 60 years. We thank the Saskatchewan Research Council for the BOREAS radiation measurements, and Alan Barr for maintaining the BERMS radiation measurements at the Old Aspen site. We are grateful for suggestions from Richard Asselin and three reviewers that improved the manuscript.

\section{References}

Bechtold, P., J.-P. Chaboureau, A. Beljaars, A. K. Betts, M. Miller, M. Köhler, M. Miller, and J.-L. Redelsperger (2004), The simulation of the diurnal cycle of convective precipitation over land in a global model, Quart. J. Roy. Meteorol. Soc., 130, 3119-3137.

Bechtold, P., M. Köhler, T. Jung, F. Doblas-Reyes, M. Leutbecher, M. J. Rodwell , F. Vitart, and G. Balsamo (2008), Advances in simulating atmospheric variability with the ECMWF model: From synoptic to decadal time-scales, Quart. J. Roy. Meteorol. Soc., 134, 1337-1351, doi:10.1002/qj.289.

Betts, A. K. (1982), Saturation Point Analysis of Moist Convective Overturning, J. Atmos. Sci., 39, 1484-1505.

Betts, A. K. (2003), Diurnal Cycle. Encyclopedia of Atmospheric Sciences, edited by J. R. Holton, J. Pyle, and J. A. Curry, pp. 640-643, Academic Press, London.

Betts, A. K. (2004), Understanding hydrometeorology using global models, Bull. Amer. Meteorol. Soc., 85, 1673-1688.

Betts, A. K. (2006), Radiative scaling of the nocturnal boundary layer and the diurnal temperature range, J. Geophys. Res., 111, D07105, doi:10.1029/2005JD006560.

Betts, A. K. (2007), Coupling of water vapor convergence, clouds, precipitation, and land-surface processes, J. Geophys. Res., 112, D10108, doi:10.1029/ 2006JD008191.

Betts, A. K. (2009), Land-surface-atmosphere coupling in observations and models, J. Adv. Model Earth Syst., 1(4), 18, doi:10.3894/JAMES.2009.1.4.

Betts, A. K. (2011), Seasonal Climate Transitions in New England, Weather, 66, 245-248 (September), doi:10.1002/wea.754.

Betts, A. K., and J. H. Ball (1995), The FIFE surface diurnal cycle climate, J. Geophys. Res., 100, 25,679-25,693.

Betts, A. K., and J. H. Ball (1997), Albedo over the boreal forest, J. Geophys. Res., 102, 28,901-28,910.

Betts, A. K., and J. H. Ball (1998), FIFE surface climate and site-average dataset: 1987-1989, J. Atmos. Sci., 55, 1091-1108.

Betts, A. K., and J. C. Chiu (2010), Idealized model for changes in equilibrium temperature, mixed layer depth and boundary layer cloud over land in a doubled $\mathrm{CO}_{2}$ climate, J. Geophys. Res., 115, D19108, doi:10.1029/ 2009JD012888.

Betts, A. K., and M. A. F. Silva Dias (2010), Progress in understanding landsurface-atmosphere coupling from LBA research, J. Adv. Model. Earth 
Syst., 2(6), 20, doi:10.3894/JAMES.2010.2.6. http://james.agu.org/index. php/JAMES/article/view/v2n6/JAMES.2010.2.6.

Betts, A. K, and P. Viterbo (2005), Land-surface, boundary layer and cloudfield coupling over the south-western Amazon in ERA-40, J. Geophys. Res., 110, D14108, doi:10.1029/2004JD005702.

Betts, A. K., J. H. Ball, and J. H. McCaughey (2001), Near-surface climate in the boreal forest, J. Geophys. Res., 106, 33,529-33,542, doi:10.1029/ 2001JD900047.

Betts, A. K., J. Fuentes, M. Garstang, and J. H. Ball (2002), Surface diurnal cycle and Boundary Layer structure over Rondonia during the rainy season, J. Geophys. Res., 107(D20), 8065, doi:10.1029/2001JD000356.

Betts, A. K., J. Ball, A. Barr, T. A. Black, J. H. McCaughey, and P. Viterbo (2006), Assessing land-surface-atmosphere coupling in the ERA-40 reanalysis with boreal forest data, Agric. Forest Meteorol., 140, 355-382, doi:10.1016/j.agrformet.2006.08.009.

Betts, A. K., R. Desjardins, and D. Worth (2007), Impact of agriculture, forest and cloud feedback on the surface energy balance in BOREAS, Agric. Forest Meteorol., 142, 156-169, doi:10.1016/j.agrformet.2006.08.020.

Bolton, D. (1980), The computation of the equivalent potential temperature, Mon. Wea. Rev., 108, 1046-1053.

Dee, D. P., et al. (2011), The ERA-Interim reanalysis: configuration and performance of the data assimilation system, Quart. J. Roy. Meteorol. Soc., 137, 553-597, doi:10.1002/qj.828.

Gameda, S., B. Qian, C. A. Campbell, and R. L. Desjardins (2007), Climatic trends associated with summerfallow in the Canadian Prairies, Agric. Forest Meteorol., 142, 170-185, doi:10.1016/j.agrformet.2006.03.026.

Karl, T. R., G. Kukla, and G. Gavin (1987), Recent temperature changes during overcast and clear skies in the United States, J. Clim. Appl. Meteorol., 26, 698-711.
Karl, T. R., G. Kukla, V. N. Razuvayev, M. J. Changery1, R. G. Quayle, R. R. Heim Jr., D. R. Easterling, and C. B. Fu (1991), Global warming: Evidence for asymmetric diurnal temperature change, Geophys. Res Lett., 18, 2253-2256, doi:10.1029/91GL02900.

Krakauer, N. Y. (2012), Estimating Climate Trends: Application to United States Plant Hardiness Zones, Advances in Meteorology, Article ID 404876, 9 pages, doi:10.1155/2012/404876.

Leathers, D. J., M. A. Palecki, D. A. Robinson, and K. F. Dewey (1998) Climatology of the daily temperature range annual cycle in the United States, Clim. Res., 9, 197-211.

MANOBS (2013), Environment Canada MANOBS, Chapter 1, Sky. http:// www.ec.gc.ca/manobs/default.asp?lang=En\&n=A1B2F73E-1.

Qian, B., X. Zhang, K. Chen, Y. Feng, and T. O'Brien (2009), Observed Long-Term Trends for conditions in Canada, J. Appl. Meteorol. Climatol., 49, 604-618, doi:10.1175/2009JAMC2275.1.

Qian, B., S. Gameda, X. Zhang, and R. De Jong (2012), Changing growing season observed in Canada, Clim. Change, 112, 339-353, doi:10.1007 s10584-011-0220-8

Shrestha, B. M., R. L. Raddatz, R. L. Desjardins, and D. E. Worth (2012), Continuous Cropping and Moist Deep Convection on the Canadian Prairies, Atmosphere, 3, 573-590, doi:10.3390/atmos3040573.

Uppala, S. M., et al. (2005), The ERA-40 reanalysis, Quart. J. R. Meteorol. Soc., 131, 2961-3012.

Wang, K., and R. E. Dickinson (2012), A review of global terrestrial evapotranspiration: Observation, modeling, climatology, and climatic variability, Rev. Geophys., 50, RG2005, doi:10.1029/2011RG000373.

Wang, A., and X. Zeng (2013), Development of global hourly 0.5-degree land surface air temperature datasets, J. Climate, doi:10.1175/JCLI-D 12-00682.1, (in press). 